\title{
Review of close-range three-dimensional laser scanning of geological hand samples
}

\author{
R. Hudson, F. Faraj and G. Fotopoulos \\ Queen's University, Department of Geological Sciences and Geological Engineering, Kingston, \\ Ontario, Canada
}

\begin{abstract}
The morphological study of geological hand samples has a wide variety of applications in the geosciences, which is conventionally accomplished by measuring the distance between features of interest on the sample's surface. Close-range three-dimensional (3D) laser scanners provide an opportunity to study the form and shape of geological samples in a digital environment and have been increasingly utilized in fields such as paleontology, rock mechanics, and sedimentology, with some uptake in planetary sciences and structural geology. For paleontological studies, primary applications are in quantitative analysis of fossil morphology and integration into 3D animated models for understanding species movements. In the field of rock mechanics, typical uses of 3D digital geological hand sample models include quantifying joint roughness coefficient (JRC), determining the surface roughness of rock samples, and assessing morphological changes over time due to processes such as weathering. In the field of sedimentology, such models are incorporated to characterize the shape of sediment particles and to calculate key parameters such as bulk density. This paper aims to provide a comprehensive review of established literature that includes substantial use of digital geological hand samples acquired from $3 \mathrm{D}$ close-range $(<1 \mathrm{~m}$ target distance) triangulation laser scanners in an effort to identify opportunities for future progress (such as global data sharing) as well as challenges specific to the nature of geological samples (e.g., translucency) and geoscientific workflows (on and off-site).
\end{abstract}

Keywords: geology, scanning, morphology, models, rocks, fossils 


\section{Introduction}

Morphology, the study of structure or form, of geological hand samples, including fossils, rocks, minerals, and sediments, has a variety of applications. For instance, the morphology of fossils aids in the identification of species (Lyons et al., 2000; Arakawa et al., 2002; Bethoux et al., 2004; Lee et al., 2018) and simulations of locomotion (Rybczynski et al., 2008; Evans and Fortelius, 2008; Polly and MacLeod, 2008). For handspecimen sized rock samples, the roughness of its surface or joints allow for the calculation of shear strength (resistance of rock joints to shearing) and transmissivity (ability of water to travel through joints) (Lanaro et al., 2000; Fardin et al., 2001; Hong et al., 2008; Yang and Kulatilake, 2019). Centimeter-scale features on the surface of rock samples, such as folds or faults indicate stress conditions (Dunham and Crider, 2012). Certain minerals may be distinguished by studying their morphology, which can be accomplished by rotating a three-dimensional (3D) model to orientations that make the distinguishing features visible or apparent (De Paor, 2016). The morphology of sediment samples is used to assess the suitability of a sediment particle for engineering applications, such as railroad ballast (Komba et al. 2013; AnochieBoateng et al., 2013; Mvelase et al., 2016). Additional important information retrievable from this approach includes sediment particle transport history and paleoenvironment (Roussillon et al., 2009; Rossi and Graham, 2010; Hirmas et al., 2013). Established methods of assessing morphology include measuring the distances between known landmarks on a sample's surface using rulers or calipers (Atwood and Sumrall, 2012; Mike et al., 2016), using profilometers to create one-dimensional (1D) cross sections of a sample's surface (Bizjak, 2010), or visually comparing the sample to established shape charts (Hawayaka and Oguchi, 2005). Lyons et al. (2000) and Lanaro et al. (2000) were among the first to apply 3D close-range laser scanners $(<1 \mathrm{~m}$ target distance) to the study of morphology of geological materials, specifically fossils and rock joints. Over the past two decades, the spatial resolution and the achievable accuracy of data point locations in three-dimensional space via laser scanning has advanced, allowing for the analysis of fine $(<\mathrm{mm})$ details. In addition, 3D information can be displayed, manipulated, archived and shared efficiently. Historically, photographs and illustrations were used to communicate and preserve geometric information, which allowed for qualitative and limited quantitative analyses in 2D. Using 2D images in conjunction with 
3D digital models allows for innovative methods of quantitative analysis such as complex geometric calculations including sphericity for grain roundness or volume measurements for bulk density computations (Bernardini and Rushmeier, 2002; Bethoux et al., 2004; Petti et al., 2008). In turn, enhanced methods for sharing morphological data have been developed (De Paor, 2016 and Harvey et al., 2017). The objective of this manuscript is to provide a comprehensive review of established literature that includes substantial use of digital geological hand samples acquired from 3D close-range triangulation laser scanners. Figure 1 represents the categorization of 83 peer-reviewed manuscripts published between 2000 and 2019, where point or multi-stripe triangulation scanners were used for the digitization of hand-specimen sized geological materials $\left(\sim 10 \mathrm{~cm}^{3}\right)$. These hand samples range from $1 \mathrm{~mm}^{3}$ to $8,000 \mathrm{~cm}^{3}$ with an average size of $20 \mathrm{~cm}^{3}$ and a median long axis of $\sim 8 \mathrm{~cm}$. The use of close-range laser scanners in geology has significantly increased in the past few years with over two thirds of publications appearing in the last 5 years (since 2014). It is worth noting that there are many important studies on the use of laser scanning for virtual geological fieldtrips, generating virtual outcrops and associated applications. In addition to a review of the current literature, the authors have included results and lessons learned from scanning 180 geological hand samples (fossils, rocks, minerals, core, sediments) as exemplars for identifying and supporting important topics for discussion. 


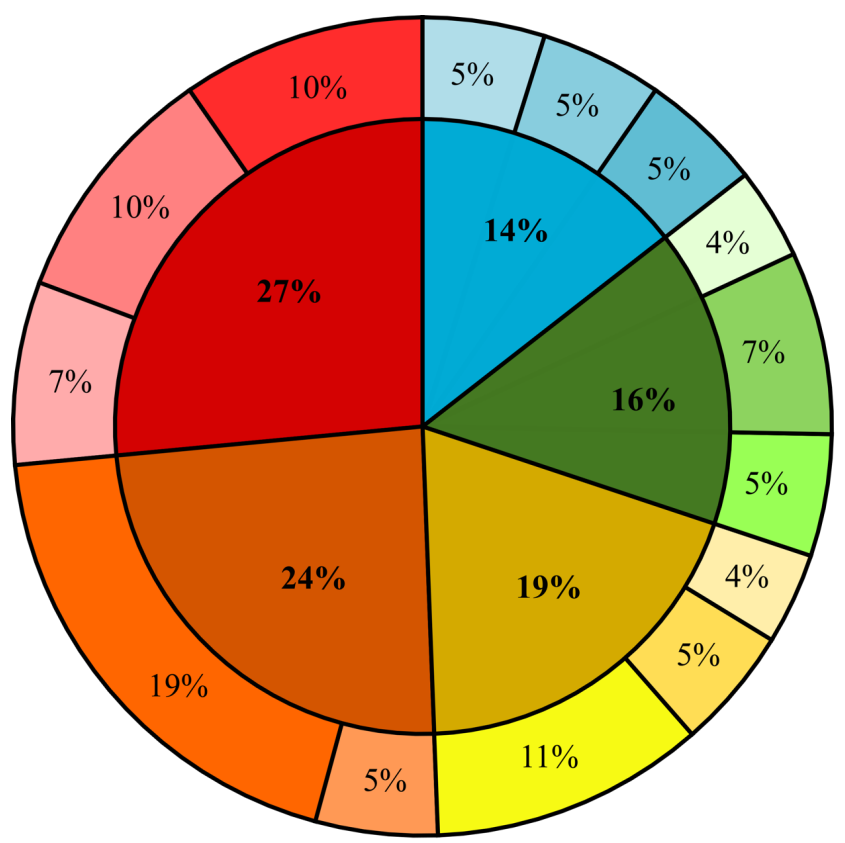

(a)

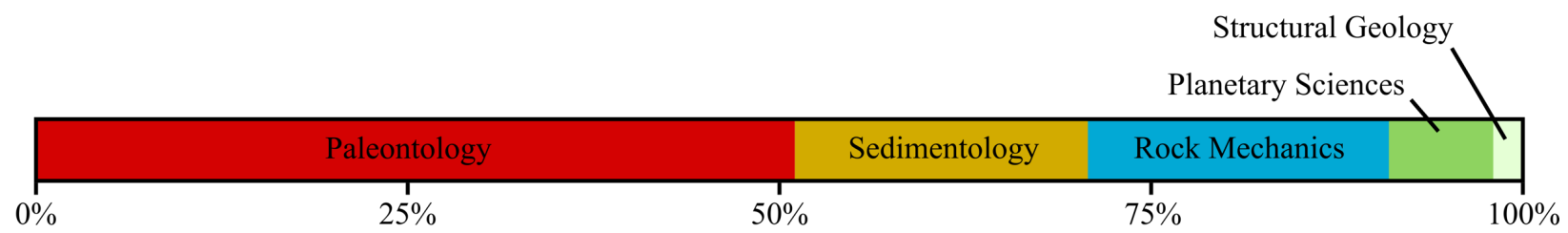

(b)

Figure 1: Proportion of the 83 peer-reviewed manuscripts published between 2000 - 2019 that apply closerange $(<1 \mathrm{~m}$ target distance) laser scanners to geological hand samples per field of study. This figure illustrates the relative proportions of papers categorized by (a) scanning target and (b) geological subdiscipline.

\section{Close-range 3D triangulation laser scanning of geological hand samples}

Non-contact laser scanners collect 3D data by measuring distances between the scanner and the target surface using directed laser beams (Kanade and Asada, 1981) typically in the 450-1550 nm wavelength range (Angelopoulou and Wright, 1999; Amann et al., 2001). For the purposes of this manuscript, "closerange" laser scanners collect point data from a maximum target distance of one meter. In general, there are three different laser scanning techniques, which include time-of-flight, phase-shift, and triangulation (Vosselman and Maas, 2010). The most common method used for close-range laser scanning is 
triangulation due to its relatively high capture point density $\left(10-100 \mathrm{pt} / \mathrm{mm}^{2}\right.$; Guidi et al., 2010) and accuracy $(2.25 \mu \mathrm{m}-200 \mu \mathrm{m}$; Blais, 2004). Close-range 3D laser scanners can be generally categorized by the capture point density measured in points per area and the number of divisions or rotations. The ranges for these parameters vary depending on the scanner, with capture point density adaptable between $1.2 \mathrm{pts} / \mathrm{in}^{2}$ $\left(0.002 \mathrm{pts} / \mathrm{mm}^{2}\right)$ and $268,000 \mathrm{pts} / \mathrm{in}^{2}\left(415 \mathrm{pts} / \mathrm{mm}^{2}\right)$ for any given scan. The number of divisions indicates the number of times a given sample is rotated on the target platform and scanned to capture the entire sample in $360^{\circ}$ and is adaptable between 4 and 16 divisions $\left(90^{\circ}\right.$ and $\left.22.5^{\circ}\right)$. In this study, 180 geological hand samples of various types were scanned and resulting models were assessed for quality and completeness leading to an average capture point density of $\sim 7,000 \mathrm{pts} / \mathrm{in}^{2}\left(\sim 11 \mathrm{pts} / \mathrm{mm}^{2}\right)$ and 12 divisions as sufficient default parameters with changes required for rougher and/or morphologically more complex samples. Increasing the number of divisions also increases the average amount of overlap per division. For the recommended 12 divisions, the average amount of overlap per division would be $150^{\circ}$, assuming the target surface is a sphere. The complexity increases as the realistic morphologies of geological hand samples are considered and it is also affected by the initial orientation of the sample.

Triangulation-based laser scanning systems emit a laser beam, either continuously or as a pulse, directed towards a target surface, as depicted in Figure 2. Not shown in this figure is the rotating platform that the target is placed on. In most cases, the angle of the emitted laser will rotate as shown with the scanning angle or a pattern will make multiple readings on the CCD sensor (Collado, 2004). A single beam or a series of striped, gridded, or patterned beams can be used (Jarvis, 1983). Upon arrival at the target surface, the beam is scattered and the waves that are reflected back to the scanner are focused by a lens within the scanner onto a charge-coupled device (CCD). The position that the beam strikes the CCD is recorded (Rioux, 1984) and the target's location with respect to the laser source is calculated. The baseline $(B)$ is known, as are the angle of projection $(a)$ and the angle of incidence $(\beta)$. The known distance between the camera lens and the $\mathrm{CCD}$ is given by $f$, in the $\mathrm{x}$-direction, and $p$, in the z-direction (Reid et al., 1988; Beraldin et al., 2009). Eq. (1) is used to calculate the distance between the laser source and the object in the z-direction $(Z)$. 


$$
Z=\frac{B * f}{p+f \tan \alpha}
$$

Basic trigonometric principles are applied to calculate the target distance between the laser source and the sample in the $\mathrm{x}$-direction $(X)$, as follows:

$$
X=Z * \tan \alpha
$$

The recorded information for each point on the target surface generates a point cloud with local 3D coordinates.

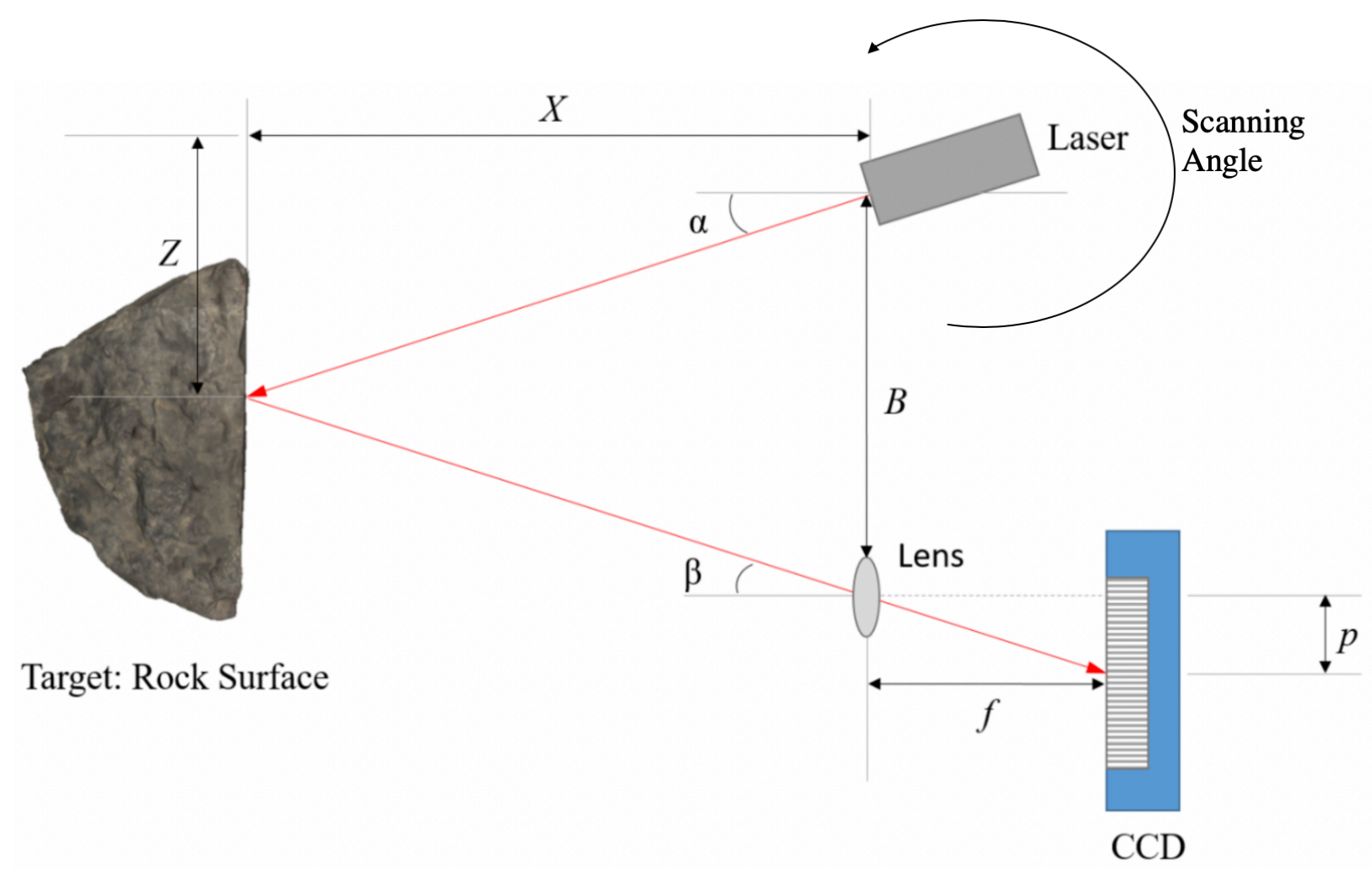

*image not to scale

Figure 2: Schematic of a close-range triangulation laser scanner layout with a rock hand sample (on a rotating platform not shown here) as the target surface - plan view (modified from Beraldin et al., 2009).

Sensitivity refers to the level (high/low) of detected backscattered signals, which correlates with gaps in data and resolution quality. Based on empirical results, it was found that reflected beams from translucent geological materials such as quartz and fluorite are generally low in intensity and may result in gaps in the 
generated point cloud model. The spatial resolution dictates the scale of target features that are resolvable in the generated point cloud model. Together, the sensitivity and spatial resolution are delineating characteristics of a laser scanner (Blais et al., 2000). The peak detection algorithm is used to record the return signals with the strongest amplitude and variations in the internal peak detection algorithm and the signal-to-noise ratio are limiting factors in scanning results (Cosarca et al., 2009). Random errors can be introduced from constructive interference caused by the summation of light waves of the reflected laser beam on the CCD (Baribeau and Rioux, 1991). This creates a high or low intensity signal, called speckle, which is difficult to resolve and lowers the overall accuracy (Amann et al., 2001; Feng et al., 2001) and reduces the resolution of the final point cloud. While the calibration of each laser scanner can vary depending on the manufacturer (Isheil et al., 2010, Santolaria et al., 2009), studies have shown that the achievable accuracy in practice may differ (Boehler and Marbs, 2003; Lichti, 2007; Lichti and Skaloud, 2010; Polo and Felicisimo, 2012). Recommended calibration steps include scanning objects with known dimensions and comparing the digital results to the physical measurements (i.e. caliper measurements) to look for bias (Mills and Fotopoulos, 2013; Zhang et al., 2014). Based on the number of divisions, closerange laser scanners take several individual scans in order to capture the complete 3D object and photographs can be simultaneously captured and registered to the $3 \mathrm{D}$ point cloud, creating a texture map. The individual scans and corresponding texture are aligned within the same reference frame (Park and DeSouza, 2005). Alignment is started by selecting at least three common points between each individual scan to define the transformation of two overlapping scans (Bernardini and Rushmeier, 2002). After selecting at least three common points, automated methods are used to fine-tune the alignment through methods such as the iterative closest point (ICP) algorithm (Besl and McKay, 1992), which minimizes the differences between overlapping point clouds. Extraneous data, such as the scanning platform, can be trimmed from the point cloud (Axelsson, 1999). Finally, the aligned scans are integrated or fused together into a single point cloud producing a unified, non-redundant surface (Levoy et al., 2000). The fused point cloud and related texture map is defined as a "3D digital model" throughout this manuscript. 
A number of factors need to be considered during the process of laser scanning of geological specimens. The quality of the generated point-cloud model is affected by conditions such as lighting as well as the distance and angle between scanner and target (Isheil et al., 2011). In general, lower lighting conditions are preferable over high ambient radiation as the latter creates noise, reducing the signal-to-noise ratio (Boehler and Marbs, 2003; Schaefer and Inkpen, 2010). High incident angles $\left(>40^{\circ}\right)$ result in both a lower signalto-noise ratio of the laser beam and an elongated footprint of the beam, meaning the resolution of the point is lower and the reflected signal is weaker in intensity (Soudarissanane et al., 2009). Therefore, placing the surface of interest directly parallel to the scanner produces the highest quality results. For larger samples that do not fit within the $40^{\circ}$ incident angle range, multiple scans of the object are necessary to accurately capture the complete face.

Empirical results from the scans of various geological hand samples $(\sim 180)$ showed that reflective or translucent samples and those with complex morphology are the most challenging for generating 3D digital models. Retro-reflective materials such as minerals with a metallic luster, for instance galena or pyrite (reflectivity of over 40\%; Folinsbee, 1949), are generally not suitable for scanning because they reflect the laser beam signal at an intensity which exceeds the limits of the sensor's dynamic range. This saturates the receiver, creating a truncated signal, which cannot be used to accurately calculate the target's position. Translucent materials, such as minerals that have a vitreous luster, such as cerussite or fluorite, are challenging to scan because the laser beam can interact with the object in a variety of ways, i.e., the laser beam can be absorbed or transmitted rather than reflected by the translucent object resulting in no point measurements. Additionally, the laser beam can be scattered within the translucent object's volume. Since the measured backscattered beam will not originate from the target's surface, the position measurements will be inaccurate. Coating reflective or translucent objects in talc powder creates an opaque surface allowing for a higher proportion of the directed laser beams to be reflected and registered for a 3D digital model. Figure 3 compares the 3D model of a galena mineral scanned prior and after talc powder application, which shows that applying talc powder resulted in a 30\% reduction in data loss. A more comprehensive 
study involving 32 scans of two different pyrite and galena samples revealed that, on average, data gaps are reduced by $35 \%$ after the application of talc powder depending on the sample's reflectivity and morphology.

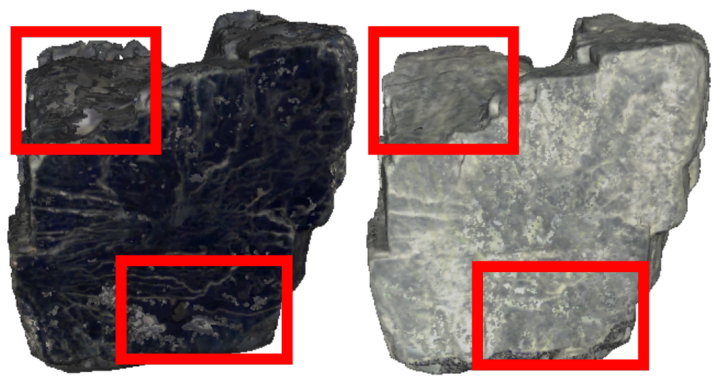

(a)

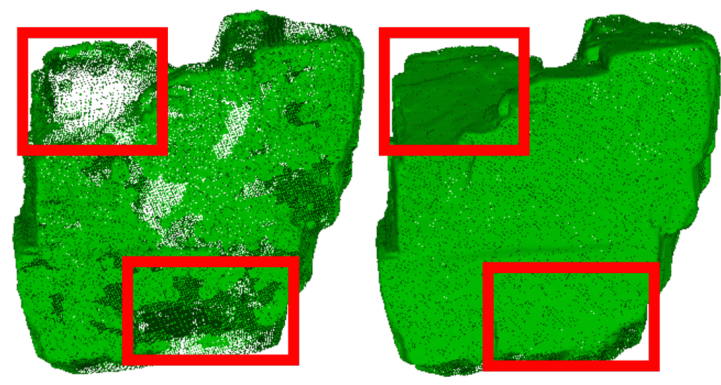

(b)

Figure 3: 3D model of a galena sample scanned at 7,000 pts/in ${ }^{2}\left(11 \mathrm{pts} / \mathrm{mm}^{2}\right)$ (a) texture map without talc (left) and with talc (right) and (b) point cloud without talc (left) and with talc (right). Two regions with the greatest reduction in data gaps after talc application are outlined in red.

Features which obstruct parts of the hand sample may cause the occluded parts to be poorly (if at all) captured in the 3D digital model. For instance, samples with a vesicular or botryoidal texture, such as the malachite sample shown in Figure 4, require a higher capture point density in order to obtain a denser point cloud to improve the likelihood that the rounded bulges, sharp edges or slightly obstructed features will be captured. Figure 4 shows a low $\left(1,900 \mathrm{pts} / \mathrm{in}^{2}\right)\left(3 \mathrm{pts} / \mathrm{mm}^{2}\right)$, medium $\left(29,000 \mathrm{pts} / \mathrm{in}^{2}\right)\left(45 \mathrm{pts} / \mathrm{mm}^{2}\right)$ and high $\left(67,000 \mathrm{pts} / \mathrm{in}^{2}\right)\left(104 \mathrm{pts} / \mathrm{mm}^{2}\right)$ capture point density scan of a hand sample of malachite, with each increase in capture point density resulting in more scanning time and greater file size. 
(a)
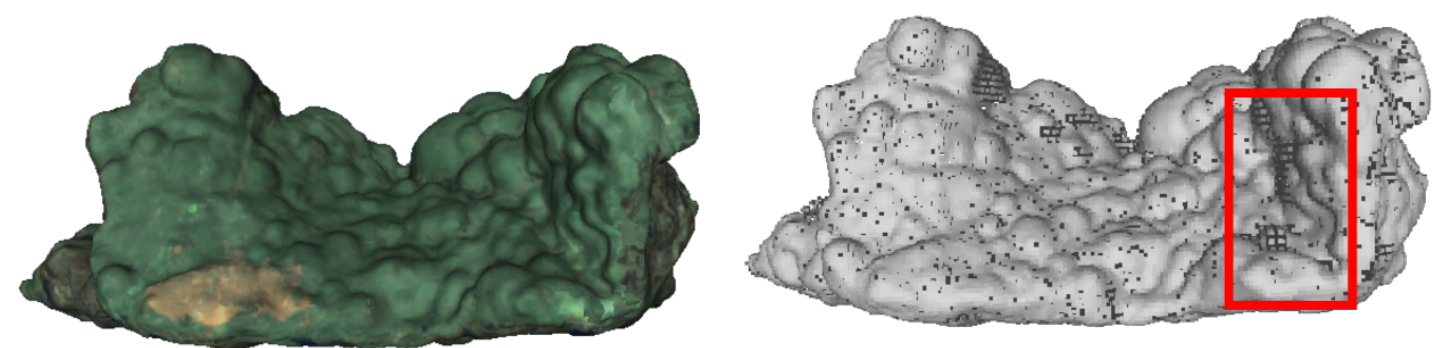

(b)
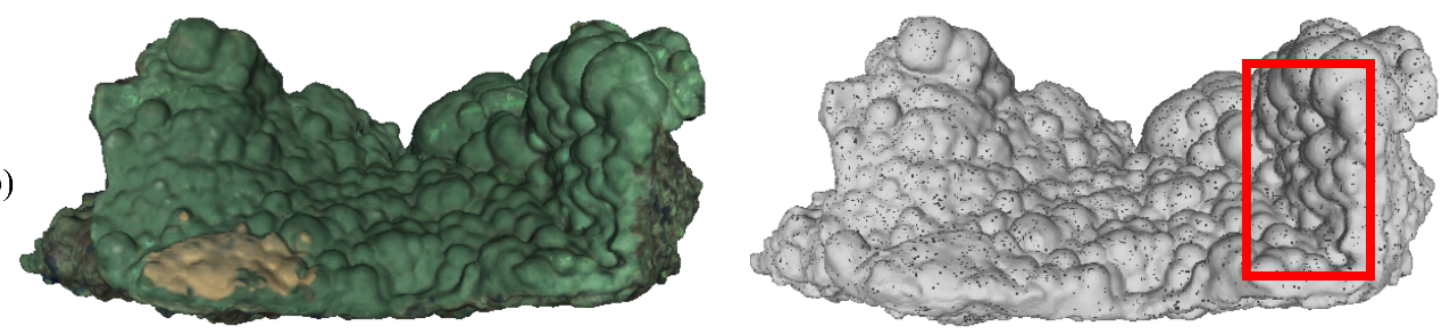

(c)
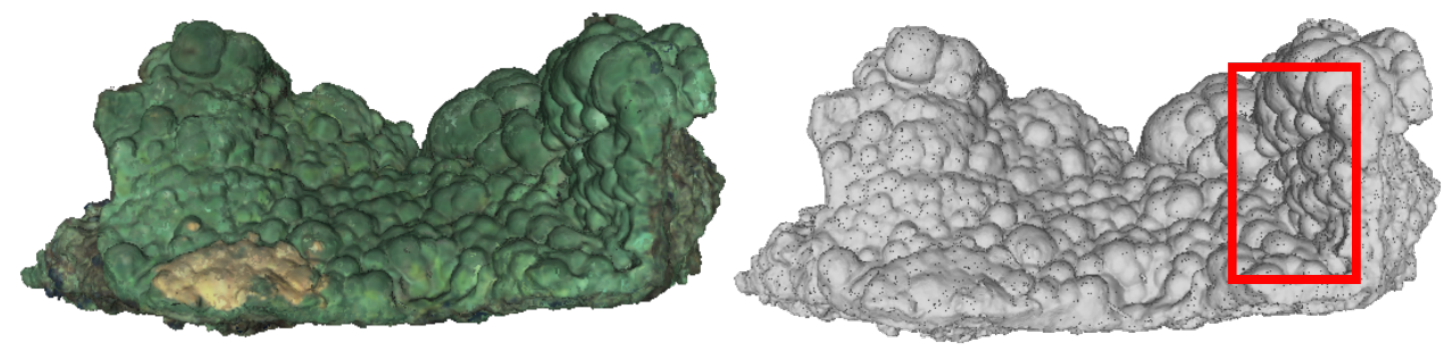

$2 \mathrm{~cm}$

Figure 4: Texture map (left) and point cloud (right) of malachite mineral sample at various capture point densities: (a) low $\left(1,900 \mathrm{pt} / \mathrm{in}^{2}\right)\left(3 \mathrm{pts} / \mathrm{mm}^{2}\right)$, (b) medium $\left(29,000 \mathrm{pt} / \mathrm{in}^{2}\right)\left(45 \mathrm{pts} / \mathrm{mm}^{2}\right)$, (c) high $(67,000$ $\left.\mathrm{pt} / \mathrm{in}^{2}\right)\left(104 \mathrm{pts} / \mathrm{mm}^{2}\right)$. With increasing capture point density, finer details, such as the botryoidal texture of the mineral are captured (red box shows greatest improvement in finer details).

\section{Applications of 3D digital models of geological hand samples}

Based on a comprehensive review of the literature in the past two decades (Figure 1), a summary of the main applications for 3D digital models of hand samples in geology is provided herein, where broad categories include fossils, trace fossils, rocks and minerals, core and sediments.

\subsection{Fossils}

Lyons et al. (2000) were among the first to apply a close-range 3D laser scanner to the digitization of body fossils or the preserved remains of past species in order to establish whether 3D laser scanning would be a viable option for paleontological studies. Since the physical form of the fossil is one of the most important 
defining features, an accurate representation is crucial. In this study, the basisphenoid and basioccipital bones of a juvenile Tylosaurus were scanned using a 3D laser scanner developed by the Institute for Information Technology, a division of the National Research Council of Canada. The basisphenoid and basioccipital bones were selected because they both have complex surfaces with small features indicating the locations of cranial nerves. It was found that scanning at a $0.1 \mathrm{~mm}$ resolution was adequate for the morphological study of fossil samples. In other studies, 3D printed specimens from scanned models were used to allow for greater interactions by students and the public to appreciate scale and take measurements (Grant et al., 2017) for Megalodon teeth and to represent missing parts of skeletons for museum display (Mitsopoulou et al., 2015).

\subsubsection{Reconstruction and analysis of ancient organism biomechanics}

Evans and Fortelius (2008) used a Nextec Hawk laser scanner to model fine-scale movements and relative position of teeth surfaces during chewing of eight different carnivoran species. Evidence from the 3D digital skull models showed that attrition wear facets were the result of tooth-tooth contact during chewing. In addition, the models showed that the amount of horizontal movement in the chewing cycle depended on the number and complexity of the species' teeth. Rybcynski et al. (2008) incorporated a 3D digital model of the Hadrosaur skull scanned using an Arius 3D laser scanner at a resolution of 0.3-0.5 mm. Simulations of various chewing scenarios constrained by the geometry of the Hadrosaur skull were evaluated and it was found that if the Hadrosaur used a transverse chewing stroke, proving this species to have had an evolutionary edge over other species. In a follow-up to this study, Cuthbertson et al. (2012) described the morphology of the intracranial joints of both Edmontonosaurus regalis and Brachylophosaurus Canadensis. Based on the morphology of these joints, as well as the observed dental wear, a new chewing hypothesis was developed for Hadrosaurids which involved only rotational movement of the mandibles. Nabavizadeh (2014) was also interested in simulating hadrosaurid chewing motions and used eleven scanned models (using a NextEngine 3D) of hadrosauroid skulls of varying genera to determine the function of the predentary bone, which is unique to ornithischian clade dinosaurs and its overall significance was not well 
understood. Results showed that predentary bone acts as an axial point for the dentary bones to simultaneously rotate mediolaterally by studying the morphology of the predentary bone and surrounding jaw bones, as well as the predentary bone's placement within the skull.

In addition to chewing, full body locomotion can be simulated with the use of 3D digital models. Polly and MacLeod (2008) used 3D scans of ankle bones of four extinct species created using a Konica-Minolta Noncontact VIVID 910 scanner in order to determine how they walked. The principal components of each ankle bone were calculated and used to automatically determine the number of toes, the stance, and the locomotor type of each species based on comparisons to existing species. Since these three locomotion parameters were known through independent studies, the accuracy of this methodology could be assessed.

Of the twelve parameters calculated (three parameters for four species), only two were incorrect suggesting the utility of 3D digital models. Like Polly and MacLeod (2008), Béchard et al. (2014) simulated species movement through the use of 3D digital models using scans of nineteen specimens of the species Bothriolepis Canadensis (a placoderm fish) with the aim of reconstructing its thoracic armor. A more accurate description of the morphology of this species compared to previous reconstructions was produced, which was used to explore biomechanical aspects and constraints. It was determined that there was likely no mobility between the cephalic (head) and thoracic (middle body) armor, and within the thoracic armor, there was a previously undiscovered gill opening. In terms of movement, it was likely that the dorsal ridge played an important role while the pectoral fins were restricted. A Cyberware 3030 RGB 3D scanner (resolution of $0.25-0.5 \mathrm{~mm}$ ) was used to create 3D scans of the skull bones of both modern humans and Neanderthals to determine if facial features varied depending on climate (Freiss et al., 2001).

\subsubsection{Taxa identification and quantitative morphological characterization}

High resolution scans allow for the morphological study of smaller and/or more morphologically complex fossils. Kullmer et al., (2001) developed a methodology for digitization of hominid teeth using 3D laser scanning where the morphology of teeth provided information on species identity and how it ate. This, in 
turn, can provide information on its prey of preference and its environment (Massare, 1987). By digitizing the teeth, structural parameters, which were necessary for morphological analysis (e.g. cusp area or height index), could automatically be calculated. Motani (2005) applied a Konica-Minolta Noncontact VIVID 910 scanner to the digitization of the tooth crown of the Ichthyosaur, Mixosaurus. Commonly, ichthyosaur tooth crowns are conical in shape, with flattened tips. However, through the use of the 3D digital model, it was found that the Mixosaurus tooth does not have a distinct conical crown tip; rather, its shape is elongate, forming a ridge, which is thinnest at the center. This shape is unique to the Mixosaurus and can thus be used as a taxonomical identifier. In addition, wear patterns of the teeth indicated that the Mixosaurus crushed hard prey items, like shells, with its posterior teeth.

Sato et al. (2011) scanned braincase of a plesiosaur, Polycotylidae, with an Arius 3D scanner at a resolution of $0.1 \mathrm{~mm}$ to determine whether it was a member of the short-necked plesiosaur family or the long-necked branch. The 3D digital models allowed for distinguishing key identifiers, such as a key-hole shaped foramen magnum (hole in the base of the skull for the spinal cord to pass through). It was determined that the Polycotylidae more closely resembled the long-necked plesiosaurs rather than the short-necked. Scanners have also been used in examining dinosaur bones: Wright and Selden (2011) used a NextEngine 3D laser scanner to create 3D digital models of two trigonotarbid specimens. These specimens are significant because they were the first of this type of dinosaur to be found in Kansas. Using the 3D digital model, the boundaries between the fossils body segments were distinguishable. The same scanner was applied to the digitization of the main bodies, called Thecaes, of blastoids, an extinct marine animal (Atwood and Sumrall, 2012). Blastoids are small $(1-2 \mathrm{~cm})$ in size, and their landmark features are $>1 \mathrm{~mm}$. To identify the specific species of blastoid, a robust series of geometric landmarks were used. Four known species of blastoid were distinguished using the 3D digital models, and three new species were discovered. Adams (2013) scanned the skull of a crocodylilform found in the Twin Mountain formation of north-central Texas. Through studying the morphology of the skull, a new species of crocodylilform, Paluxysuchus newmani, was 
discovered. Paluxysuchus newmani is distinguishable based on the medial separation between its frontal and orbital margins, an elongated anterolateral process of the postorbital, large and rounded supratemporal fenestra and a narrow posterior ramus of the jugal. Paluxysuchus newmani was placed in the Neosuchia clade based on six synapomorphies. Mike et al. (2016) aimed to develop a quantitative way to discriminate between species of blastoids. The differences between scans of various species were calculated using Discrete Procrustes distance and three species of blastoid were accurately distinguished. Lee et al. (2018) used a NextEngine 3D laser scanner to scan and study 51 brachiopod specimens with a high convexity, which made $2 \mathrm{D}$ analysis difficult. The $3 \mathrm{D}$ morphometric approach allowed for the quantification and analysis of highly convex brachiopod shells and the developed technique could potentially be applied to other taxa, as well.

\subsubsection{Fossil reconstruction and preservation}

An important function of 3D digital models is to provide a fossil record. In-situ casts have a limited life span, while also requiring physical storage. Often fragile trace fossils are digitally preserved to overcome handling and potential damage to specimens (Adams et al., 2010, Fanti et al., 2013, Subsol et al., 2015). Fossils are rarely pristine and have been subject to deformations over time including brittle deformation (structural breakage) and plastic deformation (change in shape without breakage). Brittle deformation is usually overcome by "jigsaw puzzling" which involves placing the pieces back in their presumed original position. Boyd and Motani (2008) sought to determine if the jigsaw puzzling method was viable as samples that have experienced brittle deformation are often subject to plastic deformation as well. A scan of the skull of a Woolly Monkey taken with a Konica-Minolta Noncontact VIVID 910 scanner was digitally "broken". Simulated plastic deformation was applied to the digital skull and was reconstructed using the jigsaw puzzling method. Both a 3D digital model of the original skull and one that had been subject to simulated plastic deformation to a lesser degree were used. The two reconstructions were very similar, meaning that retrodeformations using the jigsaw method can superficially look correct even if they have been deformed. Another study involved the skeletal remains of ichnospecies, which are often incomplete 
and were recreated using proportionally accurate skeletal parts. Mitsopoulou et al. (2015) created 3D digital models of the humuerus, ulna, and tibia of the Palaeoloxodon tiliensis species (a dwarf elephant that used to live in the Mediterranean during the Pleistocene) using a FARO Platinum Arm Scanner to create a mathematical relationship between adult and juvenile skeletons. To recreate the missing bones necessary for a complete skeleton, the mathematical function was applied to the known adult bones in order to model the size of the juvenile bones. In addition, Palaeoloxodon tiliensis is commonly confused with another dwarf elephant, Palaeoloxodon antiquus. In order to determine which morphological characteristics are distinguishable, the scans of the two species was overlaid and the differences identified. Peterson and Krippner (2019) used a NextEngine 3D laser scanner to scan the tooth of a Tyrannosaurus Rex and a dorsal osteoderm of a Cretaceous crocodilian to conduct geometric measurements such as surface area and volume and to assess if 3D printing these samples would be suitable for paleontological research. It was discovered that accurate digital representations can be made for paleontological samples with a long axis size range of 5 to $15 \mathrm{~cm}$ and the 3D prints of these samples have insignificant geometric differences from the scanned fossil.

\subsection{Trace fossils}

The 3D models of fossil imprints can be used to delineate specific features and make quantitative measurements that are not accessible in 2D representations. To provide an example, a fossilized therapod footprint was scanned by the authors and is shown in Figure 5 along with the quantitative depth information extracted from the 3D digital model. In the $2 \mathrm{D}$ image, the footprint is identifiable. The $3 \mathrm{D}$ scan provides a third dimension which indicates the depth of the imprint (in this case $6 \mathrm{~mm}$ from the surface). This additional information may be used to determine more about the locomotion of the specimen (walking or running) as demonstrated in Bordy et al. (2020) with photogrammetric models. 


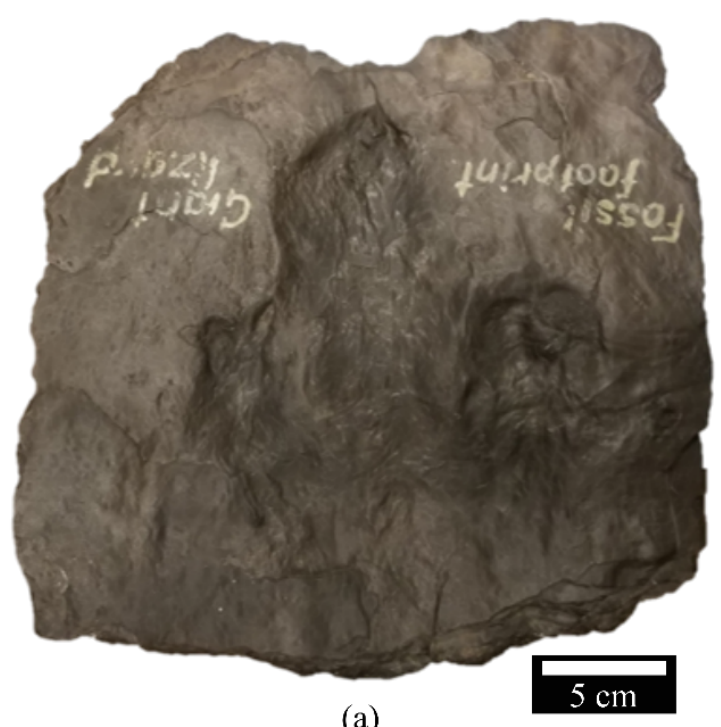

(a)

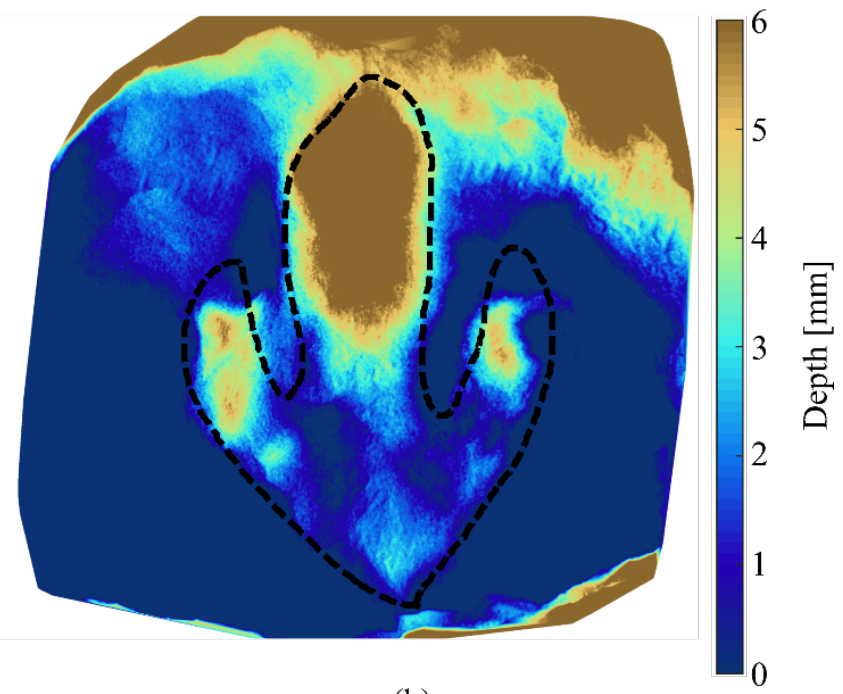

(b)

Figure 5: Single face scan of the therapod footprint at 7,000 pts/in ${ }^{2}$ showing a (a) 2D image and (b) depth model generated from the point cloud. The laser scan generated depth map illustrates the outline and topography of the footprint. Sample from the Miller Museum of Geology, Queen's University collection.

\subsubsection{Track and footprint imprints}

Trace fossils, such as footprints, burrows, or feeding marks, also provide important information on the paleoenvironment. Arakawa et al. (2002) were among the first to apply 3D laser scanning to trace fossils with three sets of therapod footprints and one set of bird footprints collected from China and Japan using a Konica-Minolta Noncontact VIVID 700 scanner. The study demonstrated that 3D laser scanning can provide geometric and topographical information on the morphology of trace fossils as an alternative traditional footprint analysis. Platt et al. (2010) used 3D scanning to quantify the morphology of several trace fossils including ant tunnels, dinosaur tracks, and insect burrows including those of a tiger beetle and a brown scorpion. New measures to quantify the morphology, including surface area index and volume exploited, were developed. Different burrow makers had characteristic surface areas and volumes and thus, these parameters could be used during taxological identification. Petti et al. $(2008 ; 2009 ; 2011)$ conducted two studies using a ShapeGrabber SG1002 3D scanner which has a resolution of $0.3 \mathrm{~mm}$ to digitize tracks in the Coste dell'Anglone tracksite in the southern Alps. Based on the depth of various digits within the footprint, interpretations were made on how the dinosaur walked. The newly discovered trackway was 
scanned and based on the morphology of the footprint, the fossils could be attributed to an archosaur trackmaker and at least three of the trackways could be assigned to the ichnogenus Brachychirothenum. This discovery is significant because this was the first well documented report of this ichnogenus from the Upper Triassic of Northern Italy. Fiorillo et al. (2010) discovered a footprint in the Nunushuk formation in Alaska. Based on 3D digital models (created using a NextEngine 3D laser scanner), it was determined that it likely belonged to a Neoceratopsian. This would not only be the earliest recorded occurrence of Neoceratopsian species in North America, but would also substantiate the Beringia land bridge theory. The theory was further corroborated by the discovery and identification, using 3D scanning, of a Therizinosaur track found in the in the Lower Cantwell formation, also in Alaska (Fiorillo and Adams., 2012). In the first of three studies applying laser scanning to footprint analysis, Belvedere and Mietto (2010) scanned footprints from Upper Jurassic Iouaride`ne ichnosite of Morocco using ShapeGrabber SG1002. The prints were assigned to the Stegosaurian ichnogenus Deltapodus based on the analysis of the digital model of the footprints. This was significant as it was the first time that this species has been discovered in Africa and indicated that there was a connection between the northern and southern parts of Tethys. Belvedere et al. (2011a) scanned casts of dinosaur tracks using a NextEngine 3D laser scanner. The goal of this study was to determine if the tracks were from avian or small non-avian dinosaurs. These tracks were significant because, if avian, they would be the oldest evidence of birds in Gondwana. This would have significant biogeographic and paleobiological implications. Using the 3D information, they were able to identify new footprints which, along with a more detailed description of the prints, allowed them to conclude that the footprints were from a small non-avian dinosaur rather than a bird. Belvedere et al. (2013) used laser scanning for footprint analysis at the Kem Kem beds and identified therapod and turtle tracks (verified in the skeletal record in different proportions). Potential explanations were that the skeletal fossils and the footprints were found in two different units or that the skeletal remains do not accurately represent the ecology of the area. Many of the skeletons used for analysis of the taxonomy of the area were purchased rather than collected by scientific research groups. Therefore, the results of these studies may be less accurate since the exact location of the remains within the strata was unknown. Footprints can provide a 
more accurate account since they are not subject to post-mortem transportation in the way that skeletons are.

In Contessi and Fanti (2012) scanned tracks from the Cenomanian Kerker Member in southern Tunisia using a Zsnapper portable scanner with a resolution of $0.2 \mathrm{~mm}$ and an accuracy of $40 \mu \mathrm{m}$. Within these tracks, which are dominated by tridactyl dinosaur tracks, three bird tracks were discovered and based on their morphology were assigned to the ichnogenus Koreananornis. These tracks were significant as they represent the oldest fossil birds from the Cretaceous of continental Africa and it is the first time that this ichnogenus has been found in Africa (previously only known in Asia and North America). The morphology of the tracks was compared to the morphology of tracks of modern birds and it was found that they were most similar to sand pipers. Sand pipers are most commonly found in modern tidal flat environments. Both the tridactyl and Koreananornis tracks indicate the presence of land in southern Tunisia which had been previously thought to be entirely marine. In their first follow-up study, Fanti et al. (2013a) scanned footprints created from silicon molds from tacks in the Wapiti Formation in Alberta, Canada. The tracksite contains a diverse ichnofauna which, in this study, were attributed to mammals, tyrannosaurids, mediumsized theropods, hadrosaurids, ankylosaurs, and amphibians. The presence of amphibians was unexpected as they were not generally found in high-latitude environments. The assemblage of this tracksite was similar to other sites of the same time period throughout western North America. In their second follow-up study, Fanti et al. (2013b) created a 3D digital model by scanning the silicon casts of representative footprints from the Hojapil-Ata tracksite located in Turkmenistan. The morphological features were run through a statistical program which showed two distinct clusters without overlap. Therefore, could quantitatively determine that there were two distinct species at this tracksite.

Fiorillo et al. (2014a) used a NextEngine 3D laser scanner to create a 3D digital model of a newly discovered track within an unnamed rock unit within the Yukon-Charley Rivers National Preserve, Alaska. The track was attributed to a hadrosaur based on its morphology. The rock unit in which the prints were found was 
dated from the late Cretaceous. This is the earliest evidence of dinosaurs in the east-central Alaska region. That same year, Fiorillo et al. (2014b) scanned a series of therapod tracks from the Lower Cantwell Formation within Denali National Park, Alaska. Two types of small to medium therapod tracks were scanned and based on their morphologies were assigned to the ichnotaxa Eubrontes and Menglongipus respectively. The findings were significant for two reasons: this was the first time that these two species had been discovered in this region, and these results indicated the presence of a multi-tiered predatory dinosaur guild structure, each providing greater detail on the paleoenvironment of the region during the Upper Cretaceous.

The study of small $(<20 \mathrm{~mm})$ tetrapod footprints is challenging as they are rarely preserved well and are often deformed. Erpetopus willistoni and Camunipes cassinisi are two such tetrapod species which are commonly mistaken for each other. Marchetti et al. (2014) scanned the footprints of these two species in order to develop a quantitative way to distinguish them. It was discovered that the separation between the two species was justified based on their differing morphology, with Erpetopus willistoni having a short digit V which curved outwards, unlike the longer and straighter digit of Camunipes cassinisi.

\subsubsection{Complete species imprints}

In addition to footprints, laser scanning can be applied to imprints of the species entire body. Bethoux et al. (2004) scanned the fossils of insect wings using a Xyris 3000 and Xyris 4000LT scanners with scanning accuracies of $30 \mu \mathrm{m}$ and $2 \mu \mathrm{m}$, respectively. The wings of an insect are typically the best-preserved structures in fossil insects and so are important for identifying taxa. Using the laser scans, the folds and veins within the wings, both important features for identification, were distinguishable. The digital models of a sample from the order Caloneaurodea collected using laser scanning indicated that this order is related to the order Orthoptera rather than Cimiciformes, hemipteroid insects, or Protorthoptera. The relationship of this order to other known orders had been a subject of debate. Antcliffe and Brasier (2008) scanned the holotype of Charnia masoni, an important fossil for studying Ediacaran biology. It was concluded that 
Charnia cannot be related to the modern cnidarian group based on the fact that these two species have opposite growth polarities evident from the species morphology. Brasier and Antcliffe (2009) scanned fossil samples of eight different Ediacaran biota including Charnia Masoni, Bradgatia, Fractofusus, Ivesheadia, Charniodiscus, Charnia wardi, Cantecedens, Beothukis mistakensis in order to develop a potential phylogeny. A phylogeny which shows the evolution of these species over time was developed by determining which fossils most closely resembled each other morphologically based on the 3D digital models. Fish feeding traces are less studied compared to other trace fossils in part because they are quite rare and often confused for different traces. One such example is the trace fossils found in the LutetianBartonian formation. The origin of these fossils has been debated. Belvedere et al. (2011a) aimed to settle this dispute by combining paleoenvironmental data and 3D scanning. Since the site was established as an open marine environment, it was unlikely that the traces were from dinosaur footprints as previously thought. The traces were determined to be very similar to those created by various types of sturgeons and, therefore, the trace maker was likely a common ancestor.

\subsection{Rocks and minerals}

De Paor (2016) discusses how 3D digital models of rocks and minerals can be used to aid in the visualization of changes such as weathering, deformation, and metamorphism. The 3D digital models of apatite, staurolite, potassium feldspar and pumice samples were generated by the authors to identify and study the scanned minerals (see Figure 6). Rotating the models of the samples revealed several features such as crystal shape, twinning, and cleavage planes. Although the physical hand sample, when available, is the penultimate specimen to identify features, in some cases (eg., for remote data sharing, educational/training purposes), the physical sample is not readily available. Thus, the dissemination of the 3D digital models allows for enhanced interactivity (compared to 2D images) with the sample and facilitates the identification and interpretation of morphological features such as vesicular textures, cleavage planes, and twinning. 


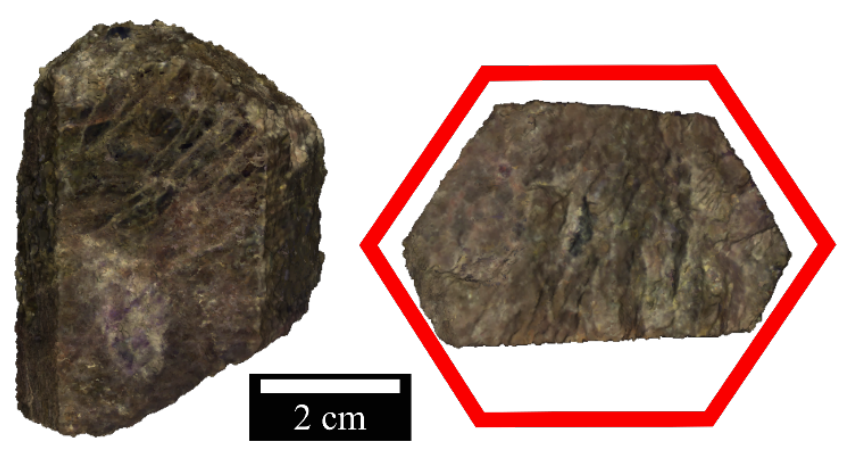

(a)

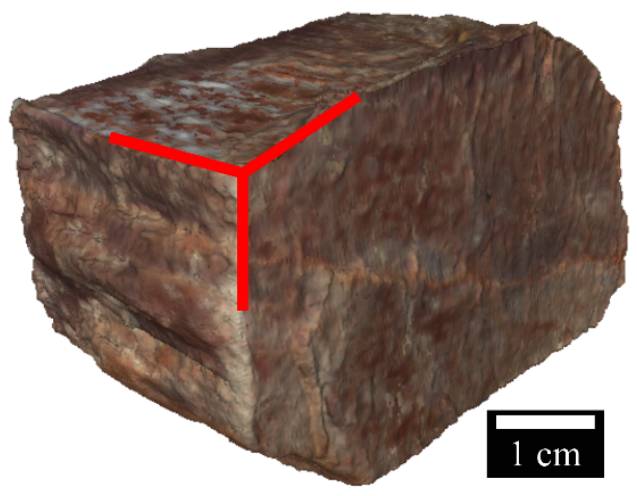

(c)

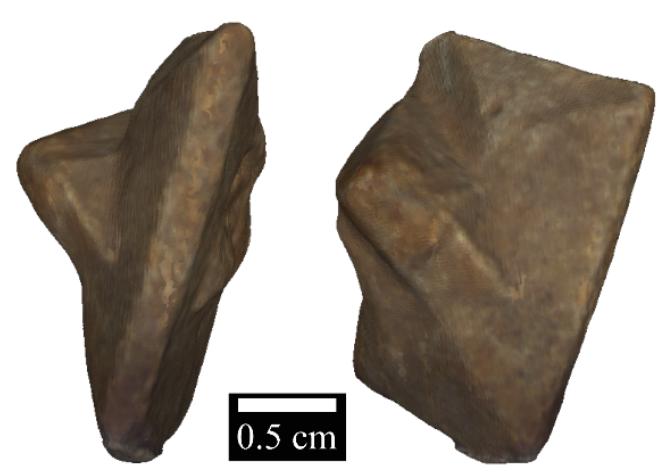

(b)

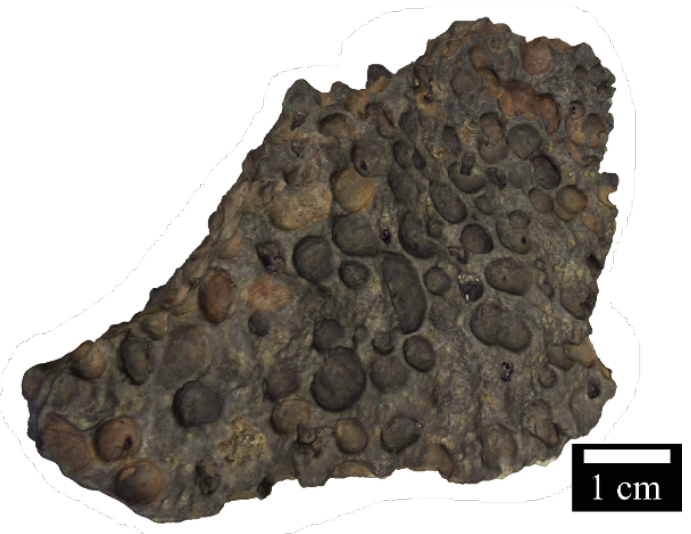

(d)

Figure 6: 3D digital samples of: (a) Apatite showing how the sample can be rotated to show the hexagonal crystal shape (outlined in red), (b) Two views of staurolite showing the twinning exhibited by the sample that is hard to identify in 2D alone, (c) Potassium feldspar rotated to show the $90^{\circ}$ cleavage planes, (d) Pumice sample showing the vesicular texture which can't be captured in a 2D image. Samples from Department of Geological Sciences and Geological Engineering, Queen's University collection.

\subsubsection{Planetary sciences}

Dufresne et al. (2013) and Poelchau et al. $(2013,2014)$ scanned rock samples that had been subjected to impacts from a metal projectile in order to simulate small scale crater impacts and determine the effects of rock type, porosity, and saturation on the morphology of impact craters. Results show that while a high porosity decreases the overall size of the crater, filling the pore space with water increases the crater size. Three rock types tested (sandstone, quartzite, and tuff) showed similar crater sizes despite having different strengths (Poelchau et al., 2014). Once these relationships have been determined on a smaller scale, they 
can be scaled to planetary-sized craters (Poelchau et al., 2014). Finally, Macke et al. (2015) used a scanner with a capture point density of $24,800 \mathrm{pts} / \mathrm{in}^{2}\left(38 \mathrm{pts} / \mathrm{mm}^{2}\right)$ and resolution of $0.1 \mathrm{~mm}$ to determine the volume of lunar samples collected from the Apollo mission. Volume calculations were used in conjunction with the sample mass in order to determine the bulk density, an important parameter for the interpretation of gravimetric data from orbiting satellites. Traditionally, the bulk density is calculated using bead emersion techniques and the laser scanner was found to be equally accurate and more efficient than the bead method. Baratoux et al. (2016) scanned a wide set of shatter cones with a Nikon MCA II 7 axis scanner in order to determine the shape term that best describes their morphology. The term "cone" was selected based on the shape of the original samples and these cones were well defined and isolated. Since then, the term has been loosely applied to other impact structures with a range of rounded fractures. It was determined that shatter cones were best described with hyperboloid to paraboloid shapes rather than conical and that shatter cone shape was not dependent on the type of lithology or impact crater size.

Fry et al. (2018) used a NextEngine laser scanner and a Konica-Minolta Vivid 9i laser camera to scan 46 fragments from 11 different iron meteorites to determine the density of each sample. The 3D laser scanners allowed for the density calculations of these 46 samples ranging in mass from $8 \mathrm{~g}$ to $156 \mathrm{~kg}$. Additionally, the bulk densities determined from the 3D scans were a good indicator of weathering effects and the presence of low-density inclusions for iron meteorites.

\subsubsection{Structural geology}

Kink bands are a distinct type of double hinged folds that result from the shearing of rocks and are traditionally described using simple two-dimensional cross sections. Dunham and Crider (2012) were the first to apply 3D laser scanning to kink bands using a FARO Arm 3D laser scanner to characterize the geometry of the kink folds in order to quantitatively distinguish the three types of intersections present (crossing, bifurcating, and obliquely diverging). This was based on parameters calculated from the 3D data such as gradient and curvature. 
The authors scanned a paragneiss sample shown in Figure 7, which was found in a mylonite zone outcrop north of Kingston, Ontario, and is part of the Miller Museum of Geology collection at Queen's University. The sample shows gneissic banding which is indicative of the regional metamorphism that affected the area during the Grenville orogeny and the geological evolution of North America as a whole based on the metamorphic and structural history. This sample was scanned to provide insight into the formational model of the Kingston area and for improved visualization (Harvey et al., 2017).

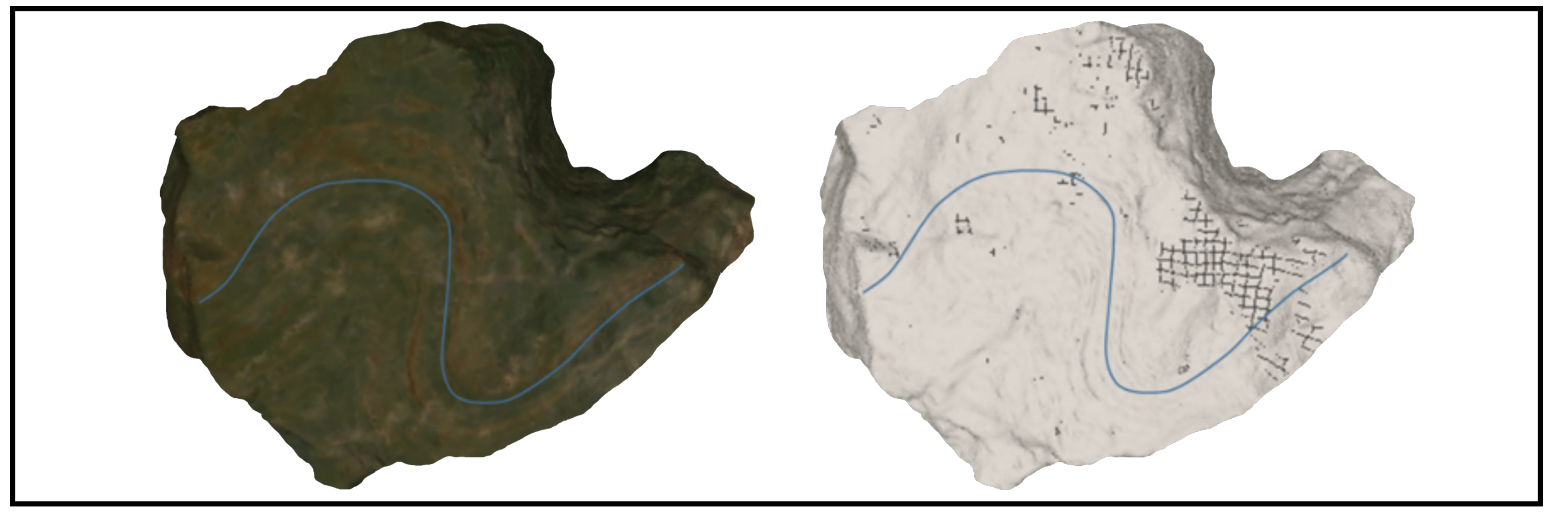

(a)

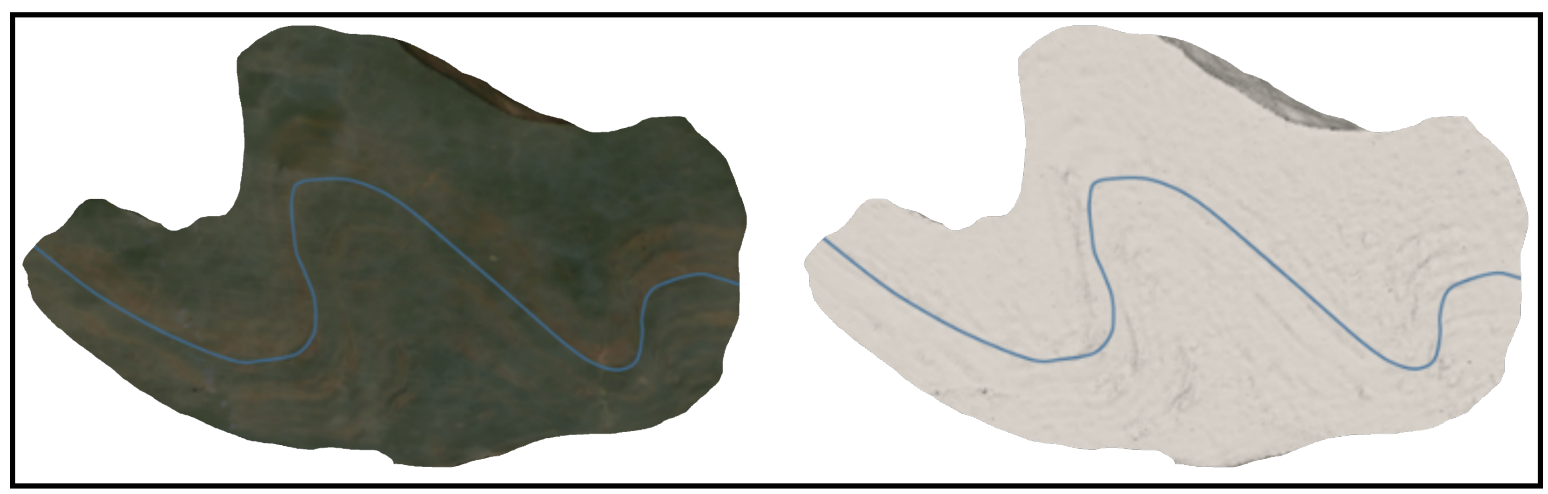

(b)

Figure 7: The texture map (left) and point cloud (right) of a Paragneiss sample from two different orientations (a) and (b) to highlight the gneissic banding on the surface of the sample. Sample from the Miller Museum of Geology, Queen's University collection (modified from Harvey et al., 2017). 


\subsubsection{Rock strength and fracture analyses}

3D laser scanned samples have been used to study how rock fractures affect the stimulation of reservoirs. Ye and Ghassemi (2018) conducted a study on four cylindrical granite samples using the CMDM88 3D laser scanner and determined that the increased permeability due to fracturing is highly dependent on fracture roughness, which could have implications for reservoir stimulation. Guo et al. (2019) used 3D scans for fracture conductivity measurements and analyzed different stimulation techniques for a carbonate gas reservoir. The use of 3D digital models resulted in understanding of the effect of fracture roughness on the permeability of rock units, which is related to the confining pressure, with rougher fractures having lower permeability at lower confining pressures.

Xu et al. (2019) and Yang and Kulatilake (2019) used a Revscan 3D and Talysurf CLI 2000 respectively to estimate the Joint Roughness Coefficient (JRC) from 3D scans and determine the effects of different parameters on rock strength. Xu et al. (2019) scanned rock samples before and after 30 days of water exposure and compared the scans to study the weakening of marble due to water interaction. Yang and Kulatilake (2019) used the Revscan 3D to scan rock surface profiles and correlate the decreasing JRC with decreasing joint persistency, which has a significant influence on the shear behavior of the tested granitic materials.

Many geotechnical tests are destructive and 3D printing can be used to conduct repeatable tests which recreate natural rock characteristics. Volger et al. (2017) repeated Brazilian tensile tests on two types of 3D printed synthetic, as well as three samples of natural sandstone at different strengths (weak, medium, and strong). The synthetic samples had a smaller range of tensile strengths than the sandstone samples and correlated best with the weak sandstone samples. The samples post-test were used to compare fracture surfaces. The printed samples showed a high correlation with the natural weak sandstone. Such studies can be used to identify suitable printing materials for recreating natural rock characteristics. Similar to geotechnical testing, weathering tests breakdown the rock samples. Bourke et al. (2008) printed samples of 
vesicular basalt cobbles. These samples were exposed to wind abrasion tests with the idea that the test on each natural sample could be repeated using the 3D printed samples. While the morphology of the real and artificial samples was similar, the material was not comparable.

\subsection{Core Samples}

3D digital models of fractured core surfaces can be used for quantitative measurements, such as approximating the JRC (Herda, 2006). The authors conducted two 3D core scans to illustrate how quantitative information can be derived from the digital models. Figure 8 shows the 3D core scans extracted from a borehole drilled in Kingston, Ontario, in 2015, with the change in depth between two fractured core surfaces mapped in mm indicating that the two samples would have significantly different JRC, which has an impact on the rock mass rating for that unit. 
(a)

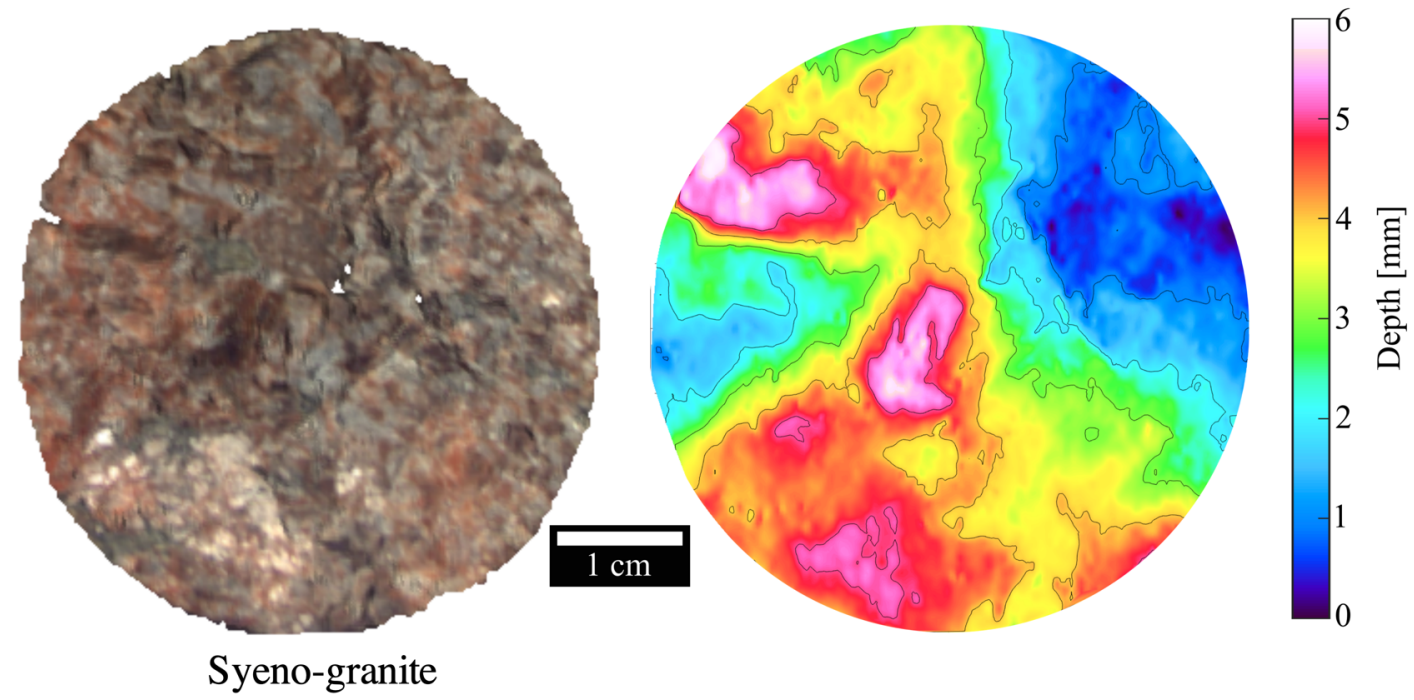

(b)

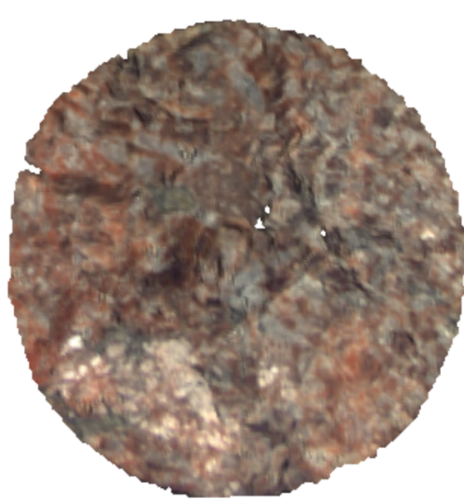

Syeno-granite

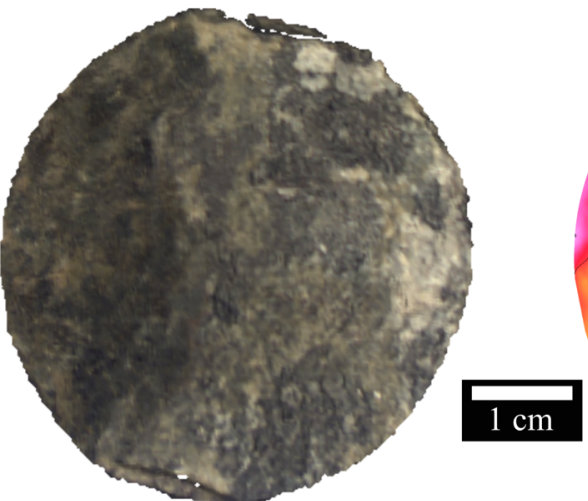

Diorite

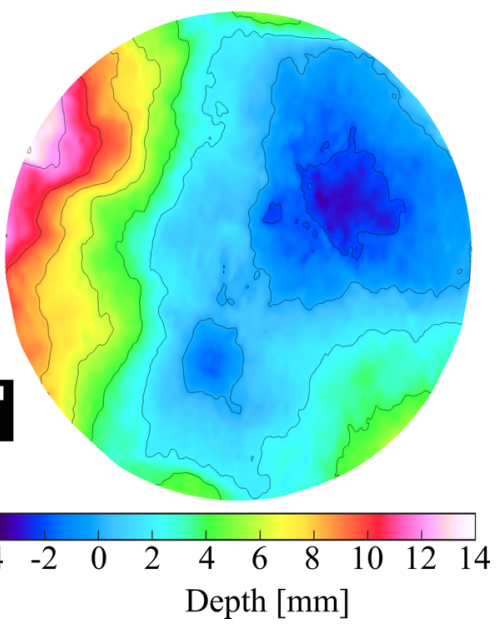

Figure 8: Scans of fractured core samples from a borehole drilled in 2015 in Kingston, Ontario. (a) quantitative depth information from a fractured core face, (b) change in depth between two different fractured core faces. Source: Miller Museum of Geology, Queen's University, logging by David Kerr.

\subsubsection{Joint surface roughness and morphology}

Surface roughness is an important rock joint property as it heavily influences shear strength and transmissivity (Fardin et al., 2001). Lanaro et al. (2000) and Fardin et al. (2001) were among the first to apply 3D laser scanners to determine the surface roughness of joints. A $1 \mathrm{~m} \times 1 \mathrm{~m}$ size cast of joint surfaces were scanned and used to explore the validity of fractal models for fracture surface morphology and the scale dependence of rock joint surface roughness. In Tam et al. (2011), the joints of granite cores at two 
different sampling lengths $(60 \mathrm{~mm}$ and $8000 \mathrm{~mm})$ were digitized using a Roland LPX-60 scanner. The calibrated roughness angles measured by the scans to peak frictional angles which were calculated using established methods. This provides a way to quantify the shearing resistance at multiple scales, which is significant as shearing resistance is highly scale dependent. Li et al (2014) used a 3D close-range laser scanner to determine the morphology of the two fracture surfaces of a joint set. A new model was developed to calculate the pressure-saturation relationship and the relative hydraulic conductivity of unsaturated fractures whose hydraulic properties had not been studied extensively.

\subsubsection{Innovative workflows for calculating the JRC}

Barton (1973) proposed a JRC to allow for the quantification of surface roughness calculated through the use of 2D profiles. Herda (2006) and Zhang et al. (2017) developed a new 3D JRC workflow based on depth generated by a 3D digital model. Results from these new methodologies to conventional techniques were comparable. Fan and Cao (2019) developed a new method for calculating the JRC using the 3D scans of rock surfaces (using a Talysurf CLI 2000 scanner) and compared the developed methodology to traditional joint roughness coefficient calculations using 15 samples. Li et al. (2019) developed a novel technique to estimate the JRC by sampling in spirals around a rock surface and used 24 samples to test the results against traditional techniques, which were affected by the anisotropy and non-uniform roughness distribution on natural joint surfaces (Handyscan 3000 scanner).

\subsubsection{Temporal analysis of core samples}

In addition to the characterization of surface morphology, laser scanning can be applied for temporal analysis to assess changes of targets of interest over time, such as studies on weathering (Birginie and Rivas, 2005; Mohtarami et al., 2017) and deformation (Indraratna et al., 2014; Zhao et al., 2017). Birginie and Rivas (2005) used a laser scanner to monitor the degradation of limestone when exposed to salt spray. Daily scans showed the four stages of deterioration: sand disaggregation, scaling, appearance of blisters, and subefflorescence, and the rates at which they occurred. Areas of degradation can be identified by comparing 
the successive scans. To quantify the rates of degradation, the standard deviation of the topographic relief and laser return intensity can be used. Comparison of degradation between rock types can then be determined. Mohtarami et al. (2017) also studied weathering effects using multi-temporal scans in order to simulate the acidic chemical solvents that are commonly used in rock engineering projects at heap leaching sites.

To quantify deformation over time, Indraratna et al. (2014) used a Konica-Minolta Noncontact VIVID 910 3D laser scanner in order to measure the asperity damage and gouge accumulation pre- and post- constant normal stiffness shear tests. 3D digital models were used to calculate the difference between scans before and after constant normal stiffness shear tests. The difference between pre- and post- test scans was calculated with negative values indicating regions of asperity damage and positive values regions of gouge accumulation. Results showed that asperity damage and gouge accumulation increase with higher initial normal stress and JRC. Zhao et al. (2017) applied a laser scanning to quantify the morphological changes of fracture surfaces after being subjected to a transient pulse test.

\subsection{Sediment Samples}

The ability to compute quantitative geometric measurements with $3 \mathrm{D}$ digital models has allowed performing such calculations as surface area, volume, sphericity, and roughness, which have several applications in the study of sediments.

\subsubsection{Grain characterization and morphological analysis}

Size and shape of sediments can provide information about the processes of fluvial transport and past environmental conditions, as well as their suitability for engineering applications. Lanaro and Tolppanen (2002) applied 3D laser scanning to quantify sediment particle shape and size. The objective of this study was to provide a new method for determining established size and shape parameters for aggregates. These parameters determine the particle's suitability for engineering applications, such as pavement layers or as 
ballast in railway tracks. Hayakawa and Oguchi (2005) scanned gravel samples with a Roland LPX-250 scanner in order to determine their sphericity and roundness. These are important parameters for determining the processes of fluvial transport and past environmental conditions that sediment experienced as the rounder the particle, the longer distance it has travelled. It was shown that the laser scanner was an effective way to measure surface area, which is used to calculate sphericity. Lee et al. (2007) aimed to further automate the laser scanning by collecting surface morphology data from aggregate particles travelling along a conveyor belt resulting in automatic calculation of shape parameters. From the scan data, the height, width, and length of each particle was computed. Angularity was calculated using mathematical morphology where the difference between a standard ellipsoid and the surface of the particles was determined.

Komba et al. (2013) and Anochie-Boateng et al. (2013) tested laser scanning, specifically the Roland LPX1200 scanner, as a new method to determine the "flakiness" of soil particles. Flakiness is defined as the ratio between the length, width, and thickness of a particle. A particle is considered flaky if one of the dimensions is significantly larger than the other two. Flaky particles are not desirable for use as construction material, specifically for railroad ballast. Results from the 3D digital model were more efficient and comparable to those calculated using the slot method (Anochie-Boateng et al., 2013). In Anochie-Boateng et al. (2011) and Mvelase et al. (2016) laser scanning data was to calculate other shape parameters, such as roundness and sphericity, to determine suitability for railroad ballast.

The morphology of lithic clasts that result from the failure of conduit wall rock provides information on the process that shaped them during eruption. Campbell et al. (2013) scanned lithic clasts from the eruption of Mount Meager, British Columbia, with a NextEngine 3D laser scanner to calculate sphericity and smoothness. The amount of surface modification, such as rounding, is proportional to the time that lithic clast spent in the conduit before eruption. It was proposed that subangular and rough clasts had shorter residence times $(<2 \mathrm{~min}$ ), and rounder, smoother clasts had longer residence times (up to $60 \mathrm{~min}$ ). The 
shape can be used to estimate the fragmentation depths and the rates of attrition during volcanic eruptions. Bagheri et al. (2014) also applied laser scanning to the quantification of the shape of irregular volcanic particles. The morphological characteristics of volcanic particles have a large influence on their threat to aviation and public health, as well as dispersion and reaction with gases and water vapor during eruption. Existing 1D and 2D shape parameters are used to estimate 3D shape parameters of the particles using caliper measurements, image analysis, the laser scans, and results from Computed Tomography (CT) scanning. The existing 1D and 2D shape parameters were compared to 3D parameters calculated using the actual 3D data. The results showed that the $2 \mathrm{D}$ variables were more accurate than the $1 \mathrm{D}$ variables $(2.4-4.6 \%$ versus $7.2-20 \%)$

\subsubsection{Soil and loose sediments}

Soil structure is of vital importance to understanding the hydrological, environmental, and ecological processes. Bulk density can be used as an indicator of soil quality as it controls the ease of root penetration, water movement, and soil strength. Rossi et al. (2008) applied a NextEngine laser scanner to determine the bulk volume of soil samples. The laser scanner results were compared to those generated from a traditional method of calculating bulk density, the paraffin-coated clod method, and showed that the results agreed well. Hirmas et al. (2013) used volume calculations from laser scanning to determine if the relationship between soil mass and soil volume could be described using fractal models on decimeter scales. Soil samples were scanned and sequentially broken between each scan. The corresponding volumes and masses were plotted against each other and fit with a power-log equation in order to determine the fractal dimension. Results showed that fractal models do in fact represent soil mass and soil volume relationships well but several orders of magnitude should be used when calculating the representative fractal dimension. Falcon-Saurez et al. (2015) scanned compacted samples of granite fines at varying water contents. The objective of this study was to determine the suitability of laser scanners to calculate dry densities of finegrained soils as compared to results from the Standard Procotor test. It was determined that the laser scanning method was applicable until a water content of less than $20 \%$, after which the fine-grained soil 
becomes too incohesive for the laser scanner to capture properly. Asahina and Taylor (2011) used a NextEngine 3D laser scanner to scan a number of both crushed and naturally rounded rock particles in order to calculate shape parameters including volume, surface area, and density. These values were compared to the results from both CT scanning and the projected area method. Since the CT scanning had the highest resolution, it was used as the truth data and it was found that the laser scanning values showed strong agreement with those generated using the CT scanning.

\subsubsection{Temporal analysis and sediment comparison}

Sediment clasts can also be affected by weathering processes and in Bourke et al. (2008) and Ehlmann et al. (2008) laser scanning was used to study weathering effects on sedimentary clasts, specifically basalt cobbles. These cobbles were scanned before and after being exposed to wind abrasion. These scans were converted into digital elevation models from which the morphological changes could be quantified and areas of preferential weathering determined. Rossi and Graham (2010) scanned granite fragments from locations within the subsurface at varying depths in order to understand the rate of porosity development in granitic rock. Solid rocks typically have low porosities but due to weathering processes, fractures and microcracks can develop over time, thus, increasing the porosity. Those closest to the surface were expected to be more weathered than samples from deeper depths. Using the laser scan models, the bulk volumes of these fragments were calculated. The bulk volumes were converted into porosity values by using the bulk density and the particle density and the equation developed by Flint and Flint (2002). Based on their porosity distribution of the particles at various depths, it was determined that clast porosity developed at a rate of $0.1 \%$ per thousand years.

\section{$4 \quad$ Summary}

Table 1 summarizes the reviewed literature on close-range 3D laser scanning of geological hand samples according to applications within the discipline. While it is clear that the availability of 3D digital models cannot and will not replace the invaluable utility of physical geological hand samples, it is worth 
contemplating where within a contemporary geological workflow 3D geological hand sample models can be exploited. To that end, the use of these models may lie with the increased ability to share data digitally. This review has identified that some collaborations among scientists working with rare and fragile samples has been facilitated through the use of digital models. At a more populous level, hosting digital geological hand sample collections online offers numerous advantages for dissemination of scientific information to the public (Rebbert, 2007; Bates et al., 2009; Carrasco et al., 2014). To date there are numerous online databases that host 3D geological hand sample models for public use (see Table 2). The 3D digital models of geological hand samples can be visualized in spatial environments in order to facilitate interpretation of the geological setting, shared digitally for efficient communication of morphological data and 3D printing allows for physical interaction (and destruction) of geological hand samples. Global databases created using collections from multiple institutions and field sites can allow for broader scale research and archiving while exploiting database management and querying capabilities. It is inevitable that the proliferation of these databases and subsequent global sharing will become ubiquitous as it allows for invaluable collaboration and communication between not only researchers but among researchers and the public. 
Table 1: Summary of the reviewed publications using close-range 3D laser scanning of hand samples in geology

\begin{tabular}{|c|c|}
\hline \multicolumn{2}{|l|}{ Fossils } \\
\hline \multicolumn{2}{|c|}{ Reconstruction and analysis of ancient organisms' biomechanics } \\
\hline $\begin{array}{l}\text { Rybczynksi et al. (2008); Evans and Fortelius (2008); } \\
\text { Cuthbertson (2012); Nabavizadeh (2014); Polly and } \\
\text { MacLeaod (2008); Béchard, (2014); } \\
\text { Freiss et al. (2001) }\end{array}$ & $\begin{array}{l}\text { Used scans of different fossils to study the motions of different species and simulate their movements } \\
\text { in 3D. Also used the scanner to reconstruct facial features and study if they correlated with the } \\
\text { paleoclimate. }\end{array}$ \\
\hline \multicolumn{2}{|c|}{ Taxa identification and quantitative morphological characterization } \\
\hline $\begin{array}{l}\text { Kullmer et al. (2002); Motani (2005); Sato et al. } \\
\text { (2011); Wright and Selden (2011); Atwood and } \\
\text { Sumrall (2012); Mike et al. (2016); Adams (2013); } \\
\text { Lee et al. (2018) }\end{array}$ & $\begin{array}{l}\text { Developed multiple methodologies for characterizing and identifying specific features of species } \\
\text { using the scanned 3D digital model. The 3D digital models were also used to identify and correct the } \\
\text { categorization of different taxonomies for multiple specimens. The depth information provided from } \\
\text { the scans allowed for quantitative analysis of sample morphology which led to the discovery of new } \\
\text { species and further categorization of similar taxa. }\end{array}$ \\
\hline \multicolumn{2}{|l|}{ Fossil reconstruction and preservation } \\
\hline $\begin{array}{l}\text { Lyons et al. (2000); Boyd and Motani (2008); } \\
\text { Mitsopoulo et al. (2015); Peterson and Krippner } \\
\text { (2019); Adams et al. (2010); Fanti et al. (2013a); } \\
\text { Subsol et al. (2015) }\end{array}$ & $\begin{array}{l}\text { Modeled the deformation and reconstructed the original fossil using the 3D digital model of the } \\
\text { incomplete specimen. Studying the scans of different specimens allowed for missing bones to be } \\
\text { identified and geometric measures to be made to recreate what the sample. The fossil scans were also } \\
\text { used for display and preservation in order to avoid potential damage to the physical specimens. }\end{array}$ \\
\hline \multicolumn{2}{|l|}{ Trace Fossils } \\
\hline \multicolumn{2}{|l|}{ Track and footprints } \\
\hline $\begin{array}{l}\text { Arakawa et al. (2002); Platt et al. (2010); Petti et al. } \\
\text { (2008; 2009; 2011); Fiorillo et al. (2010); Fiorillo and } \\
\text { Adams (2012); Belvedere and Mietto (2010); } \\
\text { Belvedere et al. (2011a); Belvedre et al. (2013); } \\
\text { Contessi and Fanti (2012); Fanti et al. (2013a); Fanti } \\
\text { et al. (2013b); Fiorillo et al. (2014a); Fiorillo et al. } \\
\text { (2014b); Marchetti et al. (2014) }\end{array}$ & $\begin{array}{l}\text { Used the 3D digital model to develop a quantitative approach for characterizing the morphology of } \\
\text { different tracks, burrows and tunnels belonging to different species. The depth map generated by } \\
\text { scanning the footprints of different species was used to discover new specimen, distinguish between } \\
\text { similar species and dinosaurs which allowed for biogeographic and paleobiological interpretations. } \\
\text { Studying the depth information from the 3D digital models also revealed more biological information } \\
\text { for the scanned specimens. }\end{array}$ \\
\hline
\end{tabular}


Bethoux et al. (2004); Antcliffe and Brasier (2008); Brasier and Antcliffe (2009); Belvedere et al. (2011b)

\section{Rocks and minerals}

\section{Planetary sciences}

Dufresne et al. (2013); (Poelchau et al., 2013, 2014);

Macke et al. (2015); Fry et al. (2018); Baratoux et al. (2016)

(2)

\section{Structural geology}

Dunham and Crider (2012); Harvey et al. (2017); De Paor (2016)

\section{Rock strength and fracture analyses}

Ye and Ghassemi (2018); Guo et al. (2019); Xu et al.

(2019); Yang and Kulatilake (2019)

\section{Core samples}

Joint surface roughness and morphology

Lanaro et al. (2000); Fardin et al. (2001); Tam et al. (2011); Li et al (2014)

Innovative workflows for calculating the JRC

Herda (2006); Zhang et al. (2017); Fan and Cao (2019); Li et al. (2019)
Reclassified certain species by studying the morphology from 3D digital models of Ediacaran biota. The scans of specie imprints also allowed for small features to be identified and classified which led to the identification of the scanned specimen.

Scanned shatter cones to study their morphology and determine if the shape was affected by lithology or impact size. Small crater impacts were also simulated by scanning rock samples which were struck by metal projectiles. The 3D digital models of various meteorites and lunar samples were also used for volume calculations.er impacts by scanning rock samples which has been struck by metal projectiles. geometry of the folds and distinguish different types of intersections. The 3D digital models were also integrated with other geological data to enhanced multiscale visualization and interpretation of geological relationships.

Conducted geotechnical tests on rock samples and used the scans of the rock fractures to analyze how they impact reservoir stimulation. Carbonate rock faces were also scanned and the resulting 3D digital model was used to determine the weakening due to water interaction.

Scanned fractured surfaces to assess the surface roughness of joints using the depth map from the scan. Multiple core was scanned to study the morphology of different fracture surfaces in a joint set and roughness angles were computed using the 3D digital model. 


\section{Temporal analysis of core samples}

Birginie and Rivas (2005); Mohtarami et al. (2017); Indraratna et al. (2014); Zhao et al. (2017)

Scanned samples before and after induced weathering to compare the 3D digital models and assess the change due to the weathering. Multiple different core samples were also scanned before and after destructive tests to assess morphological changes in the samples.

\section{Sediment samples}

\section{Grain characterization and morphological analysis}

Lanaro and Tolppanen (2002); Hayakawa and Oguchi (2005); Lee et al. (2007); Komba et al. (2013); Anochie-Boateng et al. (2013); Anochie-Boateng et al. (2011); Mvelase et al. (2016); Campbell et al. (2013); Bagheri et al. (2014)

Used the 3D digital models of different sediments to quantify the particle shape and size. The sediment scans were also used to derive geometric parameters and classify different groups of particles. Irregular particles were scanned to study and differentiate their morphological characteristics. Additionally, a quantitative approach was developed to determine the suitability of a given set of sediments for use as railroad ballast.

\section{Soil and loose sediments}

Rossi et al., (2008); Hirmas et al. (2013); Falcon-

Saurez et al. (2015); Asahina and Taylor (2011)
Computed bulk volume of several soil clots using the 3D digital model. Several granite fines were also scanned at varying water content and their volumes was used to approximate the dry density of the fine-grained soils. Crushed and naturally round rock particles were scanned to and the resulting 3D digital models were compared to assess their differences.

\section{Temporal analysis and sediment comparison}

Bourke et al. (2008); Ehlmann et al. (2008); Rossi and Graham (2010)
Scanned basalt cobbles before and after exposure to weathering to quantify the differences from the $3 \mathrm{D}$ digital models. Various granite fragments from varying depths were also scanned to assess the rate of porosity development in the sediments. 
Table 2: Summary of select online databases hosting 3D digital models of geological hand samples

\begin{tabular}{|l|l|l|}
\hline Database & Types of samples & Reference \\
\hline Great Britain 3D Project & fossils & (BGS, 2013) \\
\hline GeoFabLab & rocks and fossils & (Hasiuk, 2014) \\
\hline Smithsonian X 3D & fossils & (Smithonian Insitute, 2018) \\
\hline Smorf & crystal shapes & (Holtkamp, 2014) \\
\hline African Fossils & fossils & (African Fossils, 2018) \\
\hline Digimorph & fossils & (University of Texas, 2018) \\
\hline Mineralyze CS & core & (Mineralyze, 2020) \\
\hline NASA 3D Resources & asteroids & (NASA, 2020) \\
\hline Phenome 10k & fossils & (Phenome 10k, 2020) \\
\hline Morpho Source & fossils & (MorphoSource, 2020) \\
\hline
\end{tabular}

\section{Acknowledgements}

The authors acknowledge the Miller Museum of Geology at Queen's University for providing samples used to generate figures in this manuscript. David Kerr is acknowledged for logging the core samples. Funding for this research was provided by NSERC CREATE and NSERC DG to the third author. 


\section{References}

Adams, T. L., Strganac, C., Polcyn, M. J., \& Jacobs, L. L. (2010). High resolution threedimensional laser-scanning of the type specimen of Eubrontes glenrosensis Shuler, 1935, from the Comanchean (Lower Cretaceous) of Texas: implications for digital archiving and preservation. Palaeontol. Electron. 13(3), 1-11.

Adams, T. L. (2013). A New Neosuchian Crocodyliform from the Lower Cretaceous (Late Aptian) Twin Mountains Formation of North-Central Texas. J. Vertebrate Paleontol. 33 (1), 85-101. https://doi.org/10.1080/02724634.2012.713277.

African Fossils. (2018). African Fossils. https://africanfossils.org/ (accessed 24 November 2018).

Amann, M.C., Bosch, T. M., Lescure, M., Myllylae, R. A., Rioux, M. (2001). Laser ranging: a critical review of unusual techniques for distance measurement. Opt. Eng. 40(1), 10-20. https://doi.org/10.1117/1.1330700

Angelopoulou, E., Wright, J. (1999). Laser Scanner Technology (Report No. MS-CIS-99-16). University of Pennsylvania Department of Computer and Information Science.

Anochie-Boateng, J. K., Komba, J. J., Mvelase, G. M. (2013). Three-dimensional laser scanning technique to quantify aggregate and ballast shape properties. Constr. Build. Mater. 43, 389-398. https://doi.org/10.1016/j.conbuildmat.2013.02.062.

Anochie-Boateng, J. K., Komba, J. J., Tutumluer, E. (2011). 3D Laser based measurement of mineral aggregate surface area for South African hot-mix asphalt mixtures. In: Transportation Research Board 90th Annual Meeting Transportation Research Board.

Antcliffe, J. B., Brasier, M. D. (2008). Charnia at 50: Developmental Models for Ediacaran Fronds. Paleontol. 51 (1), 11-26. https://doi.org/10.1111/j.1475-4983.2007.00738.x.

Arakawa, Y., Azuma, Y., Kano, A., Tanijiri, T., Miyamoto, T. (2002). A new technique to illustrate and analyze dinosaur and bird footprints using 3-D digitizer. Mem. Fukui Prefect. Dinosaur Mus. 1, 7-18.

Asahina, D., Taylor, M. A. (2011). Geometry of irregular particles: Direct surface measurements by 3-D laser scanner. Powder Technol. 213 (1), 70-78. https://doi.org/10.1016/j.powtec.2011.07.008.

Atwood, J. W., Sumrall, C. D. (2012). Morphometric Investigation of the Pentremites Fauna from the Glen Dean Formation, Kentucky. J. Paleontol. 86 (5), 813-828. https://doi.org/10.1666/12003.1 .

Axelsson, P. (1999). Processing of laser scanner data-algorithms and applications. ISPRS J. Photogramm. Remote Sens. 54 (2). 138-417. https://doi.org/10.1016/S0924-2716(99)00008-8.

Bagheri, G. H., Bonadonna, C., Manzella, I., Vonlanthen, P. (2015). On the characterization of size and shape of irregular particles. Powder Technol. 270, 141-153. https://doi.org/10.1016/j.powtec.2014.10.015.

Baratoux, D., Bouley, S., Reimold, W. U., Baratoux, L. (2016). Morphometric analysis and classification of the three-dimensional geometry of shatter cones. Meteor. Planet. Sci. 51 (8), 1460-1476. https://doi.org/10.1111/maps.12610.

Baribeau, R., Rioux M. (1991). Influence of speckle on laser range finders. Appl. Opt. 30 (20), 2873-2878. https://doi.org/10.1364/AO.30.002873.

Barton, N. (1973). Review of a new shear-strength criterion for rock joints. Eng. Geol. 7 (4), 287332. https://doi.org/10.1016/0013-7952(73)90013-6.

Bates, K. T., Manning, P. L., Hodgetts, D., Sellers, W. I. (2009). Estimating Mass Properties of Dinosaurs Using Laser Imaging and 3D Computer Modelling. PLoS ONE. 4 (2), e4532. https://doi.org/10.1371/journal.pone.0004532. 
Béchard, I., Arsenault, F., Cloutier, R., Kerr, J. (2014). The Devonian placoderm fish Bothriolepis canadensis revisited with three-dimensional digital imagery. Paleontol. Electron. 17 (1), 1-19. https://doi.org/10.26879/417.

Belvedere, M., Dyke, G., Hadri, M., Ishigaki, S. (2011). The oldest evidence for birds in Northern Gondwana? Small tridactyl footprints from the Middle Jurassic of Msemrir (Morocco). Gondwana Res. 19 (2), 542-549. https://doi.org/10.1016/j.gr.2010.08.004.

Belvedere, M., Franceschi, M., Morsilli, M., Zoccarato, P. L., Mietto, P. (2011). Fish feeding traces from Middle Eocene limestones (gargano promontory, apulia, southern Italy). PALAIOS. 26 (11), 693-699. https://doi.org/10.2110/palo.2010.p10-136r.

Belvedere, M., Mietto, P. (2010). First evidence of Stegosaurian Deltapodus footprints in North Africa (Iouaridène Formation, Upper Jurassic, Morocco). Paleontol. 53 (1), 233-240. https://doi.org/10.1111/j.1475-4983.2009.00928.x.

Belvedere, M., Jalil, N. E., Breda, A., Gattolin, G., Bourget, H., Khaldoune, F., Dyke, G. J. (2013). Vertebrate footprints from the Kem Kem beds (Morocco): A novel ichnological approach to faunal reconstruction. Palaeogeogr. Palaeoclimatology, Palaeoecol. 383, 52-58. https://doi.org/10.1016/j.palaeo.2013.04.026

Beraldin, J. A. (2009). Basic theory on surface measurement uncertainty of 3D imaging systems. Three-Dimens. Imaging Metrol. 7239. https://doi.org/10.1117/12.804700.

Bernardini, F., Martin, I. M., Rushmeier, H. (2001). High-quality texture reconstruction from multiple scans. IEEE Trans. Vis. Comput. Gr. 7 (4), 318-332. https://doi.org/10.1109/2945.965346.

Bernardini, F., Rushmeier, H. (2002). The 3D Model Acquisition Pipeline. Comput. Gr. Forum 21 (2), 149-172. https://doi.org/10.1111/1467-8659.00574.

Besl P.J., McKay N.D. (1992). A Method for Registration of 3-D Shapes, IEEE Trans. Pattern Analysis and Machine Intelligence 14 (2), 239-256. https://doi.org/10.1109/34.121791.

Béthoux, O., McBride, J., Maul, C. (2004). Surface Laser Scanning of Fossil Insect Wings. Paleontol. 47(1), 13-19. https://doi.org/10.1111/j.0031-0239.2004.00344.x.

Betts, M. W., Maschner, H. D. G., Schou, C. D., Schlader, R., Holmes, J., Clement, N., Smuin, M. (2011). Virtual zooarchaeology: building a web-based reference collection of northern vertebrates for archaeofaunal research and education. J. Archeol. Sci. 38 (4), 755.e1-755.e9. https://doi.org/10.1016/j.jas.2010.06.021.

Birginie, J. M., Rivas, T. (2005). Use of a laser camera scanner to highlight the surface degradation of stone samples subjected to artificial weathering. Buil. Environ. 40 (6), 755-764. https://doi.org/10.1016/j.buildenv.2004.07.015.

Bizjak, K. F. (2010). Determining the surface roughness coefficient by 3D Scanner. Geol. 53 (2), 147-152.

Blais, F. (2004). Review of 20 years of range sensor development. J. Electron. Imaging 13 (1), 231-244. https://doi.org/10.1117/1.1631921.

Blais, F., Beraldin, J. A., El-Hakim, S. F. (2000). Range error analysis of an integrated time-offlight, triangulation, and photogrammetric 3D laser scanning system. Laser Radar Technol. Appl. V 4035, 236-248. https://doi.org/10.1117/12.397796.

Boehler, W., Vicent, M. B., Marbs, A. (2003). Investigating laser scanner accuracy. In: The International Archives of Photogrammetry, Remote Sensing and Spatial Information Sciences, 34(Part 5), 696-701. 
Bordy EM, Rampersadh A, Abrahams M, Lockley MG, Head HV (2020) Tracking the Pliensbachian-Toarcian Karoo firewalkers: Trackways of quadruped and biped dinosaurs and mammaliaforms. PLoS ONE 15(1): e0226847. https://doi.org/10.1371/journal.pone.0226847

Bourke, M., Viles, H., Nicoli, J., Lyew-Ayee, P., Ghent, R., Holmlund, J. (2008). Innovative applications of laser scanning and rapid prototype printing to rock breakdown experiments. Earth Surf. Process. Landf. 33 (10), 1614-1621. https://doi.org/10.1002/esp.1631.

Boyd, A. A., Motani, R. (2008). Three-Dimensional re-evaluation of the deformation removal technique based on "Jigsaw Puzzling." Paleontol. Electron. 11 (2), 1-7.

Brasier, M. D., Antcliffe, J. B. (2009). Evolutionary relationships within the Avalonian Ediacara biota: new insights from laser analysis. J. Geol. Soc. 166 (2), 363-384. http://dx.doi.org/10.1144/0016-76492008-011.

British Geological Survey. (2013). GB3D Type Fossils | High resolution photographs and digital models of British type fossils. Retrieved November 24, 2018, from http:/www.3dfossils.ac.uk/home.html

Campbell, M. E., Russell, J. K., Porritt, L. A. (2013). Thermomechanical milling of accessory lithics in volcanic conduits. Earth Planet. Sci. Lett. 377-378, 276-286. https://doi.org/10.1016/j.epsl.2013.07.008.

Collado J. F. (2004). New methods for triangulation-based shape acquisition using laser scanners. $\mathrm{PhD}$ Thesis, Universitat de Girona, Girona, Catalonia, Spain.

Contessi, M., Fanti, F. (2012). First Record of bird tracks in the Late Cretaceous (Cenomanian) of Tunisia. PALAIOS, 27 (7), 455-464. http://dx.doi.org/10.2110/palo.2011.p11-114r.

Cosarca, C., Jocea, A., Savu, A. (2009). Analysis of error sources in Terrestrial Laser Scanning. J. Geodesy Cadaster 11, 115-124

Cuthbertson, R. S., Tirabasso, A., Rybczynski, N., Holmes, R. B. (2012). Kinetic Limitations of Intracranial Joints in Brachylophosaurus canadensis and Edmontosaurus regalis (Dinosauria: Hadrosauridae), and Their Implications for the Chewing Mechanics of Hadrosaurids. Anat. Rec. Adv. Integr. Anat. Evol. Biol. 295 (6). 968-979. https://doi.org/10.1002/ar.22458.

De Paor, D. G. (2016). Virtual rocks. Geol. Soc. Am. Today. 26 (8), 4-11. https://doi.org/10.1130/GSATG257A.1.

Dufresne, A., Poelchau, M. H., Kenkmann, T., Deutsch, A., Hoerth, T., Schäfer, F., Thoma, K. (2013). Crater morphology in sandstone targets: The MEMIN impact parameter study. Meteor. Planet. Sci. 48 (1), 50-70. https://doi.org/10.1111/maps.12024.

Dunham, R. E., Crider, J. G. (2012). Geometric curvature analysis of intersecting kink bands: A new perspective on the 3D geometry of kink folds. J. Struct. Geol. 37, 236-247. https://doi.org/10.1016/j.jsg.2012.01.003.

Ehlmann, B. L., Viles, H. A., Bourke, M. C. (2008). Quantitative morphologic analysis of boulder shape and surface texture to infer environmental history: A case study of rock breakdown at the Ephrata Fan, Channeled Scabland, Washington. J. Geophys. Res. Earth Surf. 113, F02012. https://doi.org/10.1029/2007JF000872.

Evans, A. R., Fortelius, M. (2008). Three-dimensional reconstruction of tooth relationships during carnivoran chewing. Paleontol. Electron. 11 (2), 1-11.

Evans, C. L., Napier-Munn, T. J. (2013). Estimating error in measurements of mineral grain size distribution. Mineral. Eng. 52, 198-203. https://doi.org/10.1016/j.mineng.2013.09.005.

Falcon-Suarez, I., Sanchez-Tembleque, F., María Rivera, J., Juncosa, R., Delgado, J. (2015). Feasibility of laser scanning to determine volumetric properties of fine soils. Soils and Rocks $38,59-66$. 
Fan, W., Cao, P. (2019). A new 3d jrc calculation method of rock joint based on laboratory- scale morphology testing and its application in shear strength analysis. Bull. Eng. Geol. Environ. 79, 345-354. https://doi.org/10.1007/s10064-019-01569-0.

Fanti, F., Bell, P. R., Sissons, R. L. (2013). A diverse, high-latitude ichnofauna from the Late Cretaceous Wapiti Formation, Alberta, Canada. Cretac. Res. 41, 256-269. https://doi.org/10.1016/j.cretres.2012.12.010.

Fanti, F., Contessi, M., Nigarov, A., Esenov, P. (2013). New Data on Two Large Dinosaur Tracksites from the Upper Jurassic of Eastern Turkmenistan (Central Asia). Ichnos 20 (2), 5471. https://doi.org/10.1080/10420940.2013.778845.

Fardin, N., Stephansson, O., Jing, L. (2001). The scale dependence of rock joint surface roughness. Int. J. Rock Mech. Min. Sci. 38 (5), 659-669. https://doi.org/10.1016/S1365-1609(01)00028-4.

Feng, H.-Y., Liu, Y., Xi, F. (2001). Analysis of digitizing errors of a laser scanning system. Precis. Eng. 25 (3), 185-191 https://doi.org/10.1016/S0141-6359(00)00071-4.

Fiorillo, A. R., Decker, P. L., LePain, D. L., Wartes, M., McCarthy, P. J. (2010). A Probable Neoceratopsian Manus Track from the Nanushuk Formation (Albian, Northern Alaska)/Probable pisada de Neoceratopsia en la Formación Nanushuk (Albiense, Norte de Alaska). J. Iber. Geol. 36 (2), 165-174.

Fiorillo, Anthony R., Adams, T. L. (2012). A Therizinosaur track from the lower Cantwell Formation (Upper Cretaceous) of Denali National Park, Alaskacretaceous Therizinosaur track, Alaska. Palaios 27 (6), 395-400. https://doi.org/10.2110/palo.2011.p11-083r.

Fiorillo, A. R., Contessi, M., Kobayashi, Y. McCarthy, P. J. (2014). Theropod tracks from the lower Cantwell Formation (Upper Cretaceous) of Denali National Park, Alaska, USA with comments on theropod diversity in an ancient, high-latitude terrestrial ecosystem. New Mex. Mus. Nat. Hist. Sci. Bull. 62, 429-439.

Fiorillo, Anthony R., Fanti, F., Hults, C., Hasiotis, S. T. (2014). New ichnological, paleobotanical, and detrital zircon data from an unnamed rock unit in yukon-charley rivers national preserve (cretaceous: alaska): stratigraphic implications for the regionyukon-charley rivers n.p. dinosaur track. Palaios 29 (1), 16-26. https://doi.org/10.2110/palo.2013.054.

Flint, A. L., Flint, L. E. (2002). Particle Density. Methods of Soil Anal. 229-240. https://doi.org/10.2136/sssabookser5.4.c10.

Folinsbee, R. E. (1949). Determination of reflectivity of the ore minerals. Econ. Geol. 44 (5), 425 436. https://doi.org/10.2113/gsecongeo.44.5.425.

Friess, M. (2012). Scratching the surface? The use of surface scanning in physical and paleoanthropology. J. Anth. Sci. 90, 1-25.

Fry, C. , Samson, C. , McCausland, P. J., Ralchenko, M., McLeod, T. K. (2018). Iron meteorite bulk densities determined via 3-D laser imaging. Meteor. Planet. Sci. 53 (6), 1164-1178. https://doi.org/10.1111/maps.13067.

Grant, C. A., MacFadden, B. J., Antonenko, P., Perez, V. J. (2016). 3-D Fossils for k-12 education: a case example using the giant extinct Sharkcarcharocles Megalodon. Paleontol. Soc. Pap. 22, 197-209. https://doi.org/10.1017/scs.2017.15.

Guidi, G., Russo, M., Magrassi, G., Bordegoni, M. (2010). Performance Evaluation of $\begin{array}{lllll}\text { Triangulation Based Range } & \text { Sensors. } & \text { Sens. } & 10 & \text { (8), }\end{array}$ https://doi.org/10.3390/s100807192.

Guo, J., Ren, J., Wang, S., Chen, C., Lai, J., Gou, B. (2019). Comprehensive study of fracture flow characteristic and feasibility of hybrid volume stimulation technique in tight fractured carbonate gas reservoir. J. Pet. Sci. Eng. 174 (1), 362-373. https://doi.org/10.1016/j.petrol.2018.11.006. 
Harvey, A. S., Fotopoulos, G., Hall, B., Amolins, K. (2017). Augmenting comprehension of geological relationships by integrating 3D laser scanned hand samples within a GIS environment. Comput. Geosci. 103, 152-163. https://doi.org/10.1016/j.cageo.2017.02.008.

Hasiuk, F. (2014). Making things geological: 3-D printing in the geosciences. Geol. Soc. Am. Today. 24, 28-29. https://doi.org/10.1130/GSATG211GW.1.

Hayakawa, Y., Oguchi, T. (2005). Evaluation of gravel sphericity and roundness based on surfacearea measurement with a laser scanner. Comput. Geosci. 31 (6), 735-741. https://doi.org/10.1016/j.cageo.2005.01.004.

Herda, H. H. W. (2006). An Algorithmic 3D Rock Roughness Measure Using Local Depth Measurement Clusters. Rock Mech. Rock Eng. 39 (2), 147-158. https://doi.org/10.1007/s00603-005-0063-6.

Hirmas, D. R., Giménez, D., Subroy, V., Platt, B. F. (2013). Fractal distribution of mass from the millimeter- to decimeter-scale in two soils under native and restored tallgrass prairie. Geoderma 207-208, 121-130. https://doi.org/10.1016/j.geoderma.2013.05.009.

Holtkamp, M. (2014). Smorf crystals. http://www.smorf.nl/ (accessed 24 November 2018).

Hong, E.-S., Lee, J.-S., Lee, I.-M. (2008). Underestimation of roughness in rough rock joints. Int. J. Numer. Anal. Method. Geomech. 32 (11), 1385-1403. https://doi.org/10.1002/nag.678.

Indraratna, B., Thirukumaran, S., Brown, E. T., Premadasa, W., \& Gale, W. (2014). A technique for three-dimensional characterisation of asperity deformation on the surface of sheared rock joints. Int. J. Rock Mech. Min. Sci. 70, 483-495. https://doi.org/10.1016/j.ijrmms.2014.04.022

Isheil, A., Gonnet, J.-P., Joannic, D., Fontaine, J.-F. (2011). Systematic error correction of a 3D laser scanning measurement device. Opt. Lasers Eng. 49 (1), 16-24. https://doi.org/10.1016/j.optlaseng.2010.09.006.

Jarvis, R. A. (1983). A laser time-of-flight range scanner for robotic vision. IEEE Trans. Pattern Anal. Mach. Intel. PAMI-5 (5), 505-512. https://doi.org/10.1109/TPAMI.1983.4767429.

Kanade, T., Asada, H. (1981). Noncontact visual three-dimensional ranging devices. In: ThreeDimensional Mach. Percept. International Society for Optics and Photonics. 0283, 48-56. https://doi.org/10.1117/12.931988.

King, R. P. (1979). A model for the quantitative estimation of mineral liberation by grinding. Int. J. Mineral Process. 6 (3), 201-220. https://doi.org/10.1016/0301-7516(79)90037-1.

Komba, J., Anochie-Boateng, J., van der Merwe Steyn, W. (2013). Analytical and Laser Scanning Techniques to Determine Shape Properties of Aggregates. Transp. Res. Rec. J. Trans. Res. Board. 2335 (1), 60-71. https://doi.org/10.3141/2335-07.

Kullmer, O., Huck, M., Engel, K., Schrenk, F., Bromage, T. (2002). Hominid tooth pattern database (HOTPAD) derived from optical 3D topometry. Br. Archeol. Rep. Ser. 1049, 71-82.

Kwok, R., Cunningham, G. F., Nghiem, S. V. (2003). A study of the onset of melt over the Arctic Ocean in RADARSAT synthetic aperture radar data. J. Geophys. Res. 108, C11. https://doi.org/10.1029/2002JC001363.

Lanaro, F. (2000). A random field model for surface roughness and aperture of rock fractures. Int. J. Rock Mech. Min. Sci. 37 (8), 1195-1210. https://doi.org/10.1016/S1365-1609(00)00052-6.

Lanaro, F., Tolppanen, P. (2002). 3D characterization of coarse aggregates. Eng. Geol. 65 (1), 1730. https://doi.org/10.1016/S0013-7952(01)00133-8.

Lee, J. R. J., Smith, M. L., Smith, L. N. (2007). A new approach to the three-dimensional quantification of angularity using image analysis of the size and form of coarse aggregates. Eng. Geol. 91 (2), 254-264. https://doi.org/10.1016/j.enggeo.2007.02.003. 
Levoy, M., Pulli, K., Curless, B., Rusinkiewicz, S., Koller, D., Pereira, L., Fulk, D. (2000). The Digital Michelangelo Project: 3D Scanning of Large Statues. In: Proceedings of the 27th Annual Conference on Computer Graphics and Interactive Techniques, pp. 131-144. https://doi.org/10.1145/344779.344849.

Lee, S., Jung, J., Shi, G. R. (2018). A three-dimensional geometric morphometric study of the development of sulcus versus shell outline in Permian Neospiriferine brachiopods. Lethaia 21 (1), 1-14. https://doi.org/10.1111/let.12217.

Li, Yi, Chen, Y.-F., Zhou, C.-B. (2014). Hydraulic properties of partially saturated rock fractures subjected to mechanical loading. Eng. Geol. 179, 24-31. https://doi.org/10.1016/j.enggeo.2014.06.019.

Li, Y., Mo, P., Aydin, A., Zhang, X. (2019). Spiral sampling method for quantitative estimates of joint roughness coefficient of rock fractures. Geotech. Test. J. 42 (1), 245-255. https://doi.org/10.1520/GTJ20170213.

Lichti, D. D. (2007). Error modelling, calibration and analysis of an AM-CW terrestrial laser scanner system. ISPRS J. Photogramm. Remote Sens. 61 (5), 307-324. https://doi.org/10.1016/j.isprsjprs.2006.10.004.

Lichti, D. D., Skaloud, J. (2010). Registration and Calibration. In: G. Vosselman H.-G. Maas, Airborne and Terrestrial Laser Scanning. Dunbeath: Whittles Publishing.

Lindqvist, J., Åkesson, U. (2001). Image analysis applied to engineering geology, a literature review. Bull. Eng. Geol. Environ. 60 (2), 117-122. https://doi.org/10.1007/s100640100106.

Lyons, P., Rioux, M., Patterson, R. (2000). Application of a three-dimensional color laser scanner to paleontology: An interactive model of a juvenile Tylosaurus SP. Basisphenoid-basioccipital. Paleontol. Electron. 3 (2), 1-16.

Macke, R., J., Kent., Kiefer, W. S., Britt, D. T. (2015). 3D-Laser-Scanning technique applied to bulk density measurements of Apollo lunar samples. In: 46th Lunar and Planetary Science Conference.

Marchetti, L., Santi, G., Avanzini, M. (2014). The problem of small footrpints in paleoichnology: remarks on the Early Permian ichnotaxon Erpetopus Cassinisi, a local species from Southern Alps (Northern Italy). Res. Paleontol. Stratigr. $120 \quad$ (2), 128-132. https://doi.org/10.1080/10420940.2017.1386185.

Massare, J. A. (1987). Tooth morphology and prey preference of Mesozoic marine reptiles. J. Veterbr. Paleontol. 7 (2), 121-137. https://doi.org/10.1080/02724634.1987.10011647.

Mike, J., Sumrall, C. D., Maroulas, V., Schwartz, F. (2016). Nonlandmark classification in paleobiology: computational geometry as a tool for species discrimination. Palaeobiology 42 (4), 696-706. https://doi.org/10.1017/pab.2016.19.

Mills, G., Fotopoulos, G. (2013). On the estimation of geological surface roughness from terrestrial laser scanner point clouds. Geosph. 9 (5), 1410-1416. https://doi.org/10.1130/GES00918.1.

NASA (2020). NASA 3D Resources. https://nasa3d.arc.nasa.gov/ (accessed 04 February 2020).

African Fossils. (2018). African Fossils. https://africanfossils.org/ (accessed 24 November 2018).

Mineralyze (2020). Swedish mining innovation. https://minalyze.com/ (accessed 04 February 2020).

Mitsopoulou, V., Michailidis, D., Theodorou, E., Isidorou, S., Roussiakis, S., Vasilopoulos, T., Polydoras, S., Kaisarlis, G., Spitas, V., Stathopoulo, E., Provatidis, C., Theodorou, G. (2015). Digitizing, modelling and 3D printing of skeletal digital models of Palaeoloxodon tiliensis (Tilos, Dodecanese, Greece). Quarternary Int. 379, 4-13. https://doi.org/10.1016/j.quaint.2015.06.068. 
Mohtarami, E., Baghbanan, A., Akbariforouz, M., Hashemolhosseini, H., \& Asadollahpour, E. (2017). Chemically dependent mechanical properties of natural andesite rock fractures. Canadian Geotech. J. 55 (6), 881-893.

Motani, R. (2005). Detailed tooth morphology in a Durophagous Ichthyosaur captured by $3 \mathrm{~d}$ laser scanner. J. Vertebr. Paleontol. 25 (2), 462-465. https://doi.org/10.1671/02724634(2005)025[0462:DTMIAD]2.0.CO;2.

MorphoSource (2020). MorphoSource. https://www.morphosource.org/ (accessed 4 February 2020).

Mvelase, G. M., Anochie-Boateng, J., Msibi, L. L. (2016). Effect of round particles on shear strength properties of railway ballast. In: 15th International Conference on Railway Engineering Design and Operation.

Nabavizadeh, A. (2014). Hadrosauroid jaw mechanics and the functional significance of the predentary bone. In: The Hadrosaurs: Proceedings of the International Hadrosaur Symposium. Indiana University Press, Bloomington, Indiana, pp. 467-482.

Park, J., DeSouza, G. N. (2005). 3-D Modeling of Real-World Objects Using Range and Intensity Images. In: Apolloni B., Ghosh A., Alpaslan F., C. Jain L., Patnaik S. Machine Learning and Robot Perception. Studies in Computational Intelligence.

Peterson, J. E. Krippner, M. L. (2019). Comparisons of fidelity in the digitization and 3D printing of vertebrate fossils. J. Paleontol. Tech. 22, 1-9.

Petti, F., Avanzini, M., Belvedere, M., De Gasperi, M., Ferretti, P., Girardi, S., Tomasoni, R. (2008). Trentino Stud. Nat. Sci. Act Geol. 83, 303-315.

Petti, F. M., Avanzini, M., Nicosia, U., Girardi, S., Bernardi, M., Ferretti, P., Schirolli, P., Sasso, C. D. (2009). Late Triassic (Early-Middle Carnian) Crurotarsan tracks from the Val Sabbia Sandstone (Eastern Lombardy, Brescian Prealps, Northern Italy). Res. Paleontol. Stratigr. 115 (3), 277-290. https://doi.org/10.13130/2039-4942/6384.

Petti, F. M., Bernardi, M., Ferretti, P., Tomasoni, R., Avanzini, M. (2011). Dinosaur tracks in a marginal marine environment: the Coste dell'Anglone ichnosite (Early Jurassic, Trento Platform, NE Italy). Ital. J. Geosci. 130 (1), 27-41. https://doi.org/10.3301/IJG.2010.19.

Phenome 10k. (2020). Phenome 10k. https://phenome10k.org/ (accessed 4 February 2020).

Pierre, G., Lahousse, P. (2006). The role of groundwater in cliff instability: an example at Cape Blanc-Nez (Pas-de-Calais, France). Earth Surf. Process. Landf. 31 (1), 31-45. https://doi.org/10.1002/esp.1229.

Platt, B. F., Hasiotis, S. T., Hirmas, D. R. (2010). Use of Low-Cost Multistripe Laser Triangulation (MLT) Scanning Technology for Three-Dimensional, Quantitative Paleoichnological and Neoichnological Studies. J. Sediment. Res. $80 \quad$ (7), 590-610. https://doi.org/10.2110/jsr.2010.059.

Poelchau, M. H., Kenkmann, T., Hoerth, T., Schäfer, F., Rudolf, M., Thoma, K. (2014). Impact cratering experiments into quartzite, sandstone and tuff: The effects of projectile size and target properties on spallation. Icarus 242, 211-224. https://doi.org/10.1016/j.icarus.2014.08.018.

Poelchau, M. H., Kenkmann, T., Thoma, K., Hoerth, T., Dufresne, A., Schäfer, F. (2013). The MEMIN research unit: Scaling impact cratering experiments in porous sandstones. Meteor. Planet. Sci. 48 (1), 8-22. https://doi.org/10.1111/maps.12016.

Polo, M.-E., Felicísimo, Á. M. (2012). Analysis of Uncertainty and Repeatability of a Low-Cost 3D Laser Scanner. Sens. 12 (7), 9046-9054. https://doi.org/10.3390/s120709046.

Polly, P. D., MacLeod, N. (2008). Locomotion in fossil Carnivora: an application of eigensurface analysis for morphometric comparison of 3D surfaces. Paleontol. Electron. 11 (2), 10-13. 
Rebbert, C. (2007). The role of museums in geoscience education: A perspective. Lead. Edge 26 (10), 1322-1325. https://doi.org/10.1190/1.2794398.

Reid, G. T., Marshall, S. J., Rixon, R. C., Stewart, H. (1988). A laser scanning camera for range data acquisition. J. Phys. D: Appl. Phys. 21 (10S), S1-S3. https://doi.org/10.1088/00223727/21/10S/001.

Rioux, M. (1984). Laser range finder based on synchronized scanners. Appl. Opt. 23 (21), 38373844. https://doi.org/10.1364/AO.23.003837.

Rossi, A. M., Graham, R. C. (2010). Weathering and Porosity Formation in Subsoil Granitic Clasts, Bishop Creek Moraines, California. Soil Sci. Soc. Am. J. 74 (1), 172-185. https://doi.org/10.2136/sssaj2009.0146.

Rossi, A. M., Hirmas, D. R., Graham, R. C., Sternberg, P. D. (2008). Bulk Density Determination by Automated Three-Dimensional Laser Scanning. Soil Sci. Soc. Am. J. 72 (6), 1591-1593. https://doi.org/10.2136/sssaj2008.0072N.

Roussillon, T., Piégay, H., Sivignon, I., Tougne, L., Lavigne, F. (2009). Automatic computation of pebble roundness using digital imagery and discrete geometry. Comput. Geosci. 35 (10), 1992-2000. https://doi.org/10.1016/j.cageo.2009.01.013.

Rybczynski, N., Tirabasso, A., Bloskie, P., Cuthbertson, R., Holliday, C. (2008). A threedimensional animation model of Edmontosaurus (Hadrosauridae) for testing chewing hypotheses. Paleontol. Electron. 11 (2), 1-14.

Santolaria, J., Guillomía, D., Cajal, C., Albajez, J. A., Aguilar, J. J. (2009). Modelling and Calibration Technique of Laser Triangulation Sensors for Integration in Robot Arms and Articulated Arm Coordinate Measuring Machines. Sens. 9 (9), 7374-7396. https://doi.org/10.3390/s90907374.

Sato, T., Wu, X.-C., Tirabasso, A., Bloskie, P. (2011). Braincase of a Polycotylid Plesiosaur (Reptilia: Sauropterygia) from the Upper Cretaceous of Manitoba, Canada. J. Vertebr. Paleontol. 31 (2), 313-329. https://doi.org/10.1080/02724634.2011.550358.

Schaefer, M., Inkpen, R. (2010). Towards a protocol for laser scanning of rock surfaces. Earth Surf. Process. Landf. 35 (4), 417-423. https://doi.org/10.1002/esp. 1938.

Smith, N. E., Strait, S. G. (2008). PaleoView3D: from specimen to online digital model. Paleontol. Electron. 11 (2), 1-17.

Smithsonian Institution. (2018). Smithsonian Digitization 3D. http://www.3d.si.edu/ (accessed 24 November 2018).

Soudarissanane, S., Lindenbergh, R., Menenti, M., Teunissen, P. J. G. (2009). Incidence angle influence on the quality of terrestrial laser scanning points. In: Proceedings ISPRS Workshop Laserscanning 2009, 1-2 Sept 2009, Paris, France. ISPRS

Subsol, G., Moreno, B., Jessel, J.-P., Braga, J., Bruxelles, L., Thackeray, F., Clarke, R. (2015). In Situ 3D Digitization of the " Little Foot " Australopithecus Skeleton From Sterkfontein.

Sutherland, D. N., Gottlieb, P. (1991). Application of automated quantitative mineralogy in mineral processing. Miner. Eng. 4 (7), 753-762. https://doi.org/10.1016/0892-6875(91)900632.

Tam, C. C. Y., Kwong, A. K. L., Lee, P. K. K. (2011). Calibration of rock joint roughness and shear strength with the use of 3D laser scanning technique. HKIE Trans. 18 (4), 27-34. https://doi.org/10.1080/1023697X.2011.10668235.

University of Michigan. (2020). University of Michigan Online Repository of Fossils. https://umorf.ummp.lsa.umich.edu/wp/ (accessed 4 February 2020). 
University of Texas. (2018). Digital Morphology at the University of Texas. http://digimorph.org/index.phtml (accessed 24 November 2018).

Vogler, D., Walsh, S. D. C., Dombrovski, E., Perras, M. A. (2017). A comparison of tensile failure in 3D-printed and natural sandstone. Eng. Geol. 226, 221-235. https://doi.org/10.1016/j.enggeo.2017.06.011.

Wright, D. F., Selden, P. A. (2011). A Trigonotarbid Arachnid from the Pennsylvanian of Kansas. J. Paleontol. 85 (5), 871-876. https://doi.org/10.1666/10-126.1.

$\mathrm{Xu}$, J., Zhang, J., Liu, T. (2019). Mesoscopic weakening feature of marble during water rock interaction. Geotech. Geol. Eng. 31 (1), 121-128. https://doi.org/10.1007/s10706-018-0596-6.

Yang, X., Kulatilake, P. H. S. W. (2019). Laboratory investigation of mechanical behavior of granite samples containing discontinuous joints through direct shear tests. Arabian J. Geosci. 12 (3), 79. https://doi.org/10.1007/s12517-019-4278-3.

Ye, Z., Ghassemi, A. (2018). Injection-induced shear slip and permeability enhancement in granite

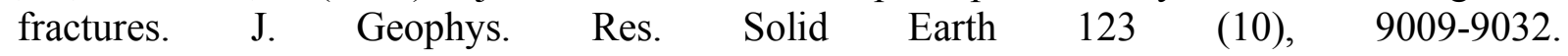
https://doi.org/10.1029/2018JB016045.

Zhang, G., Karakus, M., Tang, H., Ge, Y., Jiang, Q. (2017). Estimation of Joint Roughness Coefficient from Three-Dimensional Discontinuity Surface. Rock Mech. Rock Eng. 50, 25352546. https://doi.org/10.1007/s00603-017-1264-5.

Zhang, H., Ren, Y., Liu, C., Zhu, J. (2014). Flying spot laser triangulation scanner using lateral synchronization for surface profile precision measurement. Appl. Opt. 53 (20), 4405-4412. https://doi.org/10.1364/AO.53.004405.

Zhao, Y., Zhang, L., Wang, W., Tang, J., Lin, H., \& Wan, W. (2017). Transient pulse test and morphological analysis of single rock fractures. Int. J. Rock Mech. Min. Sci. 91, 139-154. https://doi.org/10.1016/j.ijrmms.2016.11.016. 